\title{
The Fortress Beneath: Ground Penetrating Radar Imaging of the Citadel at Alcatraz: 1. A Guide for Interpretation
}

\author{
Mark E. Everett ${ }^{1, *(\mathbb{D}}$, Timothy S. DeSmet ${ }^{2}$, Robert R. Warden ${ }^{3}$, Henry A. Ruiz-Guzman ${ }^{4}$, Peter Gavette ${ }^{5}$ \\ and Jason Hagin ${ }^{5}$ \\ 1 Department of Geology and Geophysics, Texas A\&M University, College Station, TX 77845, USA \\ 2 Department of Geological Sciences and Environmental Studies, Binghamton University, \\ Binghamton, NY 13902, USA; tdesmet@binghamton.edu \\ 3 Department of Architecture, Texas A\&M University, College Station, TX 77845, USA; r-warden@tamu.edu \\ 4 Department of Soil and Crop Sciences, Texas A\&M University, College Station, TX 77845, USA; \\ henry.ruiz@tamu.edu \\ 5 Golden Gate National Recreation Area, National Park Service, San Francisco, CA 94123, USA; \\ Peter_Gavette@nps.gov (P.G.); Jason_Hagin@nps.gov (J.H.) \\ * Correspondence: everett@geo.tamu.edu
}

Citation: Everett, M.E.; DeSmet, T.S.; Warden, R.R.; Ruiz-Guzman, H.A.; Gavette, P.; Hagin, J. The Fortress Beneath: Ground Penetrating Radar Imaging of the Citadel at Alcatraz: 1. A Guide for Interpretation. Heritage 2021, 4, 1328-1347. https://doi.org/ $10.3390 /$ heritage4030072

Academic Editor: Nicola Masini

Received: 16 June 2021

Accepted: 16 July 2021

Published: 17 July 2021

Publisher's Note: MDPI stays neutral with regard to jurisdictional claims in published maps and institutional affiliations.

Copyright: (c) 2021 by the authors. Licensee MDPI, Basel, Switzerland. This article is an open access article distributed under the terms and conditions of the Creative Commons Attribution (CC BY) license (https:// creativecommons.org/licenses/by/ $4.0 /)$.

\begin{abstract}
Ground-penetrating radar has emerged as a prominent non-destructive evaluation tool for the study of inaccessible subsurface elements of cultural heritage structures. Often of central interest is the desire to image the remains of a pre-existing historic structure that is located directly beneath a more recently built one. The interpretation of GPR images in such cases is usually difficult due to ambiguities caused by the presence of pervasive clutter, environmental noise, and overlapping target signatures. Sites with abundant ground truth allow for more confident interpretations and serve as a useful testbed to assist similar studies at other places, where little or no ground truth is available. This study reports GPR interpretations of structures belonging to the 19th century Citadel beneath the main prison cellhouse at Alcatraz. At this site, lidar scans, direct observations, and historical documents are available to facilitate identification of radar target signatures. A general interpretation of the acquired radargrams is made in this paper, while the companion paper presents more advanced analysis of target signatures based on curvelet image processing. This study points to the development of a radar facies classification scheme that is specific to cultural heritage investigations.
\end{abstract}

Keywords: ground-penetrating radar; non-destructive evaluation; subsurface imaging

\section{Introduction}

Preservation of cultural heritage is an important activity of any civilized society. Pursuant to this, in recent years a wide array of non-destructive testing tools for evaluating the condition of various aspects of the built environment have been developed [1,2]. In particular, Lai et al. [3] provide a detailed review of the history of ground-penetrating radar (GPR) use for civil engineering applications, that includes a comprehensive section on studies involving cultural heritage buildings.

In this work we discuss the interpretation of GPR data in an important historical context in which the ground-truth is mostly, although not completely, known. The interpretations described herein can serve as a guide to scientists who wish to better understand GPR data acquired at cultural heritage sites that are characterized by non-existent or poorlyknown ground truth. There should be a sufficient range of interesting subsurface targets at the present study site to stimulate the interest of most GPR practitioners. The GPR data in this paper are minimally processed, on purpose, both to preserve the generality of the discussion and to provide reassurance that useful interpretations can be made without subjecting the data to an extensive technical workflow. An example of an advanced GPR workflow based on radar-signal amplitude analysis applied to a cultural heritage 
investigation may be found in [4]. Additionally, radar signatures could be quantitatively modeled, for instance using wave-propagation simulation software such as gprMax [5] or an equivalent. This is a worthy task that would provide additional valuable insights, but unfortunately it is outside the scope of the present study.

Ground penetrating radar (GPR) is often an appropriate geophysical tool for applications that favor high vertical resolution at the expense of deep penetration. GPR imaging is accomplished by detecting the subsurface electromagnetic impedance contrasts that govern reflections, diffractions and scattering of an electromagnetic wave generated by a transmitter, normally located at or near the ground surface. In the frequency range from $10 \mathrm{MHz}$ to $2 \mathrm{GHz}$, wave propagation in resistive $(\sigma<0.01 \mathrm{~S} / \mathrm{m})$ and non-magnetic $\left(\mu=\mu_{0}\right)$ earth materials is mainly sensitive to spatial changes in dielectric permittivity $\varepsilon$ in the subsurface. The radar signal becomes attenuated by any conductive material through which the wave propagates. With systematic movement of the transmitter and receiver antennas, the signals can be combined into an image of the subsurface objects and discontinuities from which the waves have reflected, diffracted, and/or scattered.

Selection of antenna frequency is important. For example, the well-known resolution vs. range tradeoff is discussed in Davis and Annan [6]. The requirement of high resolution suggests that a high frequency antenna should be used, but high-frequency signals quickly attenuate and consequently have a smaller depth of penetration than lower-frequency signals. The GPR user must select a frequency that offers an acceptable tradeoff between resolution and depth of penetration. Some studies utilize a range of frequencies to obtain low-resolution information about deeper structures, along with higher-resolution information about shallower structures. For example, Utsi and Colls [7] used 4 radar frequencies while prospecting different aspects of the subsurface environment beneath the Holy Trinity church floor at Stratford-upon-Avon in their investigation of the early 17th century Shakespeare burial site: $250 \mathrm{MHz}$ (background soil structure); $400 \mathrm{MHz}$ (deep graves to $\sim 5 \mathrm{~m}$ depth); $1.5 \mathrm{GHz}$ (shallow graves to $\sim 1.5 \mathrm{~m}$ depth) and $4 \mathrm{GHz}$ (possible grave goods and small metal artifacts associated with coffins). Furthermore, it should be noted that the GPR response of an elongated subsurface target depends on the orientation, or polarization, of transmitter and receiver antennas with respect to the long axis of the target [8,9]; an example of this effect is shown in the results section below.

There have been many previous studies using GPR to examine historical structures. Terenzi et al. [10] used GPR to perform a structural integrity assessment of a heritage building located in an earthquake-prone region. Masini et al. [11] and Johnston et al. [12] used GPR at frequencies $1 \mathrm{GHz}$ and higher to detect internal discontinuities and facilitate evaluations of the structural integrity of historic masonry walls, pillars and columns. In these studies, the GPR apparatus was directly applied to vertical surfaces to image the internal structure of above-ground infrastructure, rather than the more traditional subsurface inspection based on radar antennas placed on the ground, which is the configuration considered herein.

It is common for non-destructive techniques to be employed in order to characterize pre-existing buildings of historical significance that have subsequently been built upon [13]. In this context, Udphuay et al. [14] conducted a GPR survey at $500 \mathrm{MHz}$ over the fine gravel floor of a Gothic abbey in southern France and mapped a number of subsurface features related to an underlying Romanesque building. Other GPR studies have identified hidden subsurface features that are essential structural components of visible above-ground items of cultural heritage. For instance, Miccinesi et al. [15] used a stepped-frequency GPR to map beneath the floor of the Accademia gallery in Florence, Italy, and revealed the circular concrete foundation supporting Michaelangelo's statue of David. Many other examples may be found in the literature.

In this paper, we demonstrate the interpretation of GPR images at a site in which a later building was built atop the basement of a pre-existing one, wherein both are now of historical significance. In many cultural heritage investigations at such locations, a certain type of historical subsurface structure is designated as a target of interest, such as a grave, a 
foundation, or a wall belonging to the pre-existing structure. However, the radar signature of a target of interest can be partially occluded by signatures of other nearby subsurface objects of lesser interest, which herein are referred to as "clutter". It should of course be noted that clutter in one investigation may actually be a target of another investigation, and vice versa. While this paper focuses on general interpretation, in the companion paper [16] we demonstrate the application of curvelet analysis [17] as a means to separate the radar signatures of some prescribed Citadel targets from those of clutter, so that the former can be studied in relative isolation.

\section{Materials and Methods}

A GPR survey was conducted in June 2016 within the cellhouse of the main prison building on Alcatraz island in San Francisco County, California. This paper describes an investigation of GPR signals that were generated due to the presence of the basement of an earlier building, the Citadel, underlying the present-day cellhouse. Ground-truthing of the GPR signals was enabled over much of the surveyed area by direct observation as stair access to the Citadel is available, as well as by comparison to historical documents [18] and publicly available lidar data acquired within the Citadel.

During the 19th century, Alcatraz island was fortified by the U.S. Army to guard the San Francisco Bay area against potential attackers arriving by sea. Construction of the defensive barracks referred to as "The Citadel" begun in 1853 and completed by 1859 (Figure 1a). During the subsequent building of the main prison (1908-1912; Figure 1b) the upper two stories of the Citadel were removed, with only its basement and the surrounding dry moat included within the architectural plan of the overlying cellhouse. The surviving Citadel basement and dry moat beneath the cellhouse is probed by GPR in this study. Thompson [19] provides a detailed history of Alcatraz island. A previous GPR survey of Alcatraz civil war-era fortifications located outside the main prison building was reported by de Smet et al. [20].

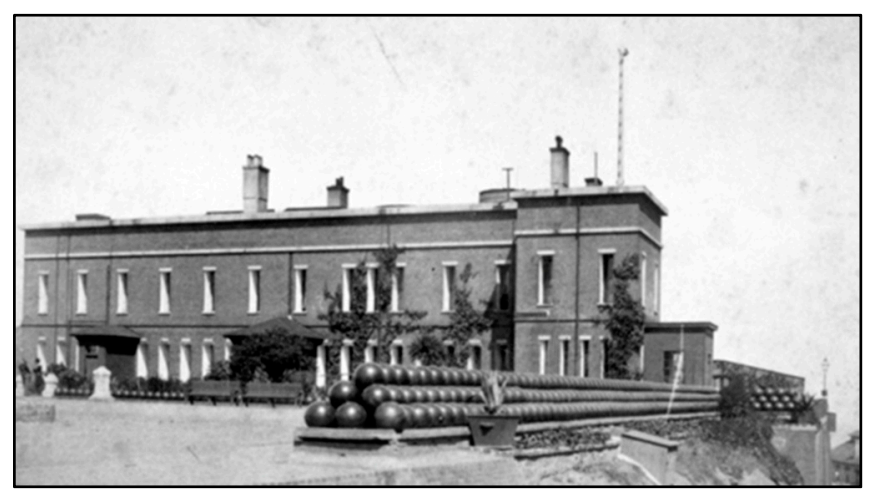

(a)

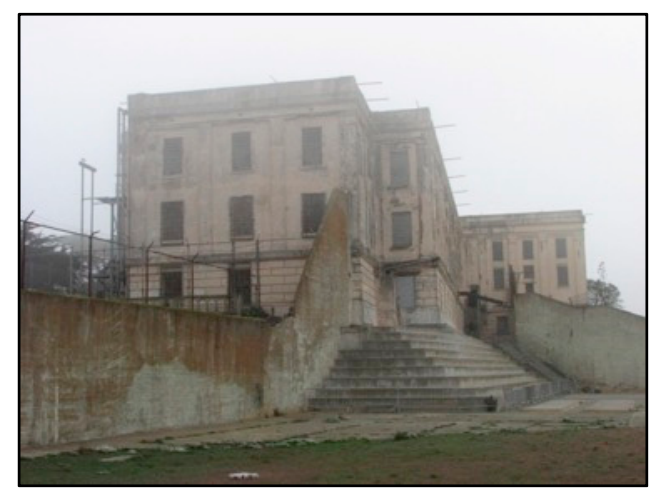

(b)

Figure 1. (a) The citadel, completed in 1859, photo taken 1885 . Credit: PARC Golden Gate National Recreation Area; (b) Main Prison building, photo taken 2013.

GPR data were collected on the floor of the cellhouse in nine areas known as Sunrise Alley, Michigan Avenue, Broadway, Park Avenue, Sunset Strip, Library, South ABC-blocks, Barbershop and Times Square (Figure 2). The surveyed areas are shaded and occupy easily accessible areas between and at the end of rows of the prison cells. It was not feasible to acquire GPR data within the confined spaces of the individual cells. The dataset was acquired during overnight hours while there were no visitors at this popular tourist destination (Figure 3). Barbershop and Times Square radar coverage will not be emphasized in this paper since those areas lie wholly outside the footprint of the Citadel, as indicated in Figure 2. South ABC-blocks is not located within the original Citadel footprint, per se, but is included herein since it overlies the "cistern additions area" (described below) that was built prior to 1882 . 
The structural elements of the Citadel have been altered several times by renovation and reinforcement works, including 1909 modifications for the new prison and extensive seismic upgrades in 2003 and 2014. These alterations are described in [21]. There is no attempt made in this paper to discriminate, based on the observed radar signatures alone, between an original structure and a later renovation or modification. Such a discrimination would have to involve detailed knowledge of the materials and construction techniques used, perhaps an estimate of the expected level of environmental degradation, and definitely supported by some element of ground truth discovery. In general, however, unexpected or unusual radar signatures could provide cultural heritage investigators with important clues that an original structure has been modified.

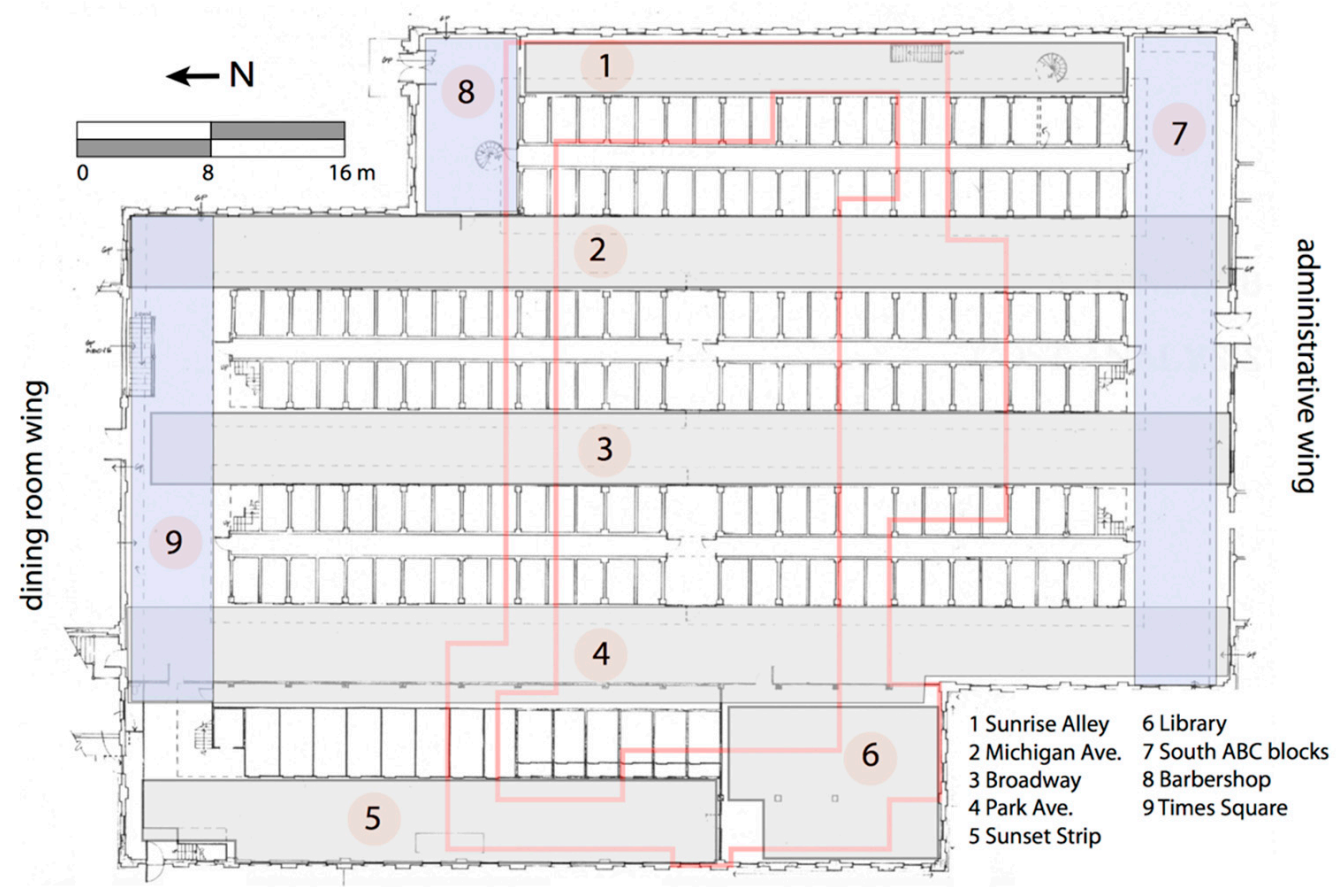

Figure 2. Floorplan of the Alcatraz cellhouse [22] showing GPR survey layout. The outline of the underlying Citadel basement and surrounding dry moat is shown in red. The shower room (not shown) lies below the cellhouse to the north of the Citadel.

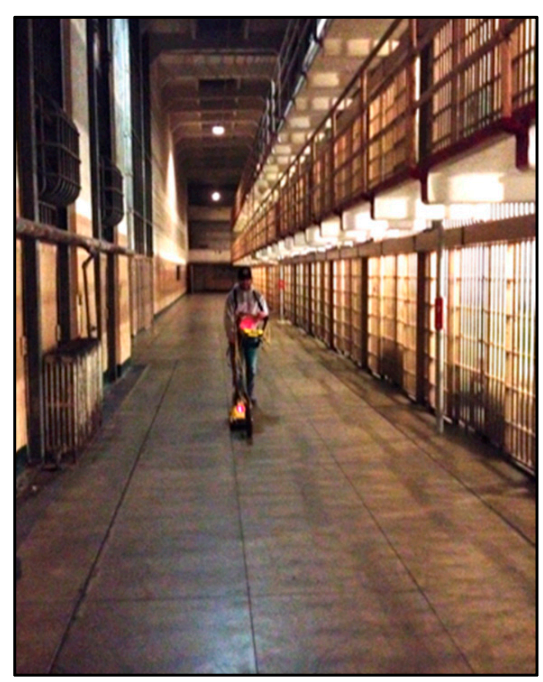

Figure 3. Overnight GPR data acquisition in the Alcatraz cellhouse. 
The equipment used for the acquisition of GPR data was the Sensors and Software ${ }^{\circledR}$ PulseEkko Pro Receiver (Model 1600) with a 100-V transmitter and $500 \mathrm{MHz}$ electricdipole antennas. Acquisition parameters included a stack number of 8 and a 100 ns time window for each trace. The processing steps included only a dewow filter to remove noninformative low-frequency signal energy, SEC gain to compensate for the signal energy loss caused by geometric spreading of the spherical wavefront, and in some cases a background subtraction to exclude the direct ground response and transmitter-receiver coupling. These standard procedures are explained in [23]. Lines of GPR data were acquired by traversing the length of conveniently divided sections of the cellhouse floor. Once the end of a line was reached the next line was offset by either $0.25 \mathrm{~m}$ or $0.50 \mathrm{~m}$, depending on the coverage area, and the acquisition proceeded in alternating directions until the full area was covered. Where an obstacle, such as a pillar preventing data acquisition, was encountered, a portion of the line was skipped, with the location of the obstacle noted.

The raw GPR data were not correctly oriented for immediate analysis, as alternating lines were acquired in opposing directions. In addition, some lines were split into multiple parts by obstacles. Some lines in the same coverage area were of different lengths due to the irregular dimensions of our partition of the accessible cell house floor, or slight irregularities in the along-profile trace sampling interval. The GPR data were first rectified so that all lines within a given coverage area were oriented in the same direction and, where appropriate, "rubber-band" interpolated [23] to become equal in length. In the case of obstacles, the display was modified with the missing segment(s) masked out.

In this study, the GPR data were compared to publicly available terrestrial laser scanning (lidar) data from inside the Alcatraz citadel. The lidar data, acquired in 2016 by Paul Davidson of the National Park Service, proved indispensable in identifying the causative structures generating signals in the GPR data. The identification is accomplished by comparing the lidar scans with both GPR sections and time/depth slices created in PulseEkko software, provided by the radar equipment manufacturer. Further interpretational aid was provided by comparisons of the GPR depth-slices (C-scans) and vertical cross-sections (B-scans) to a number of publicly available historical, architectural and engineering documents. Note that the C-scans are presented as either time-slices or depth-slices, and the vertical axes of the B-scans are marked as either depth or two-way travel time. In all cases, a radar velocity of $0.1 \mathrm{~m} / \mathrm{ns}$ was used to convert time to depth.

\section{Results}

A 2016 lidar rendering of the Citadel floor is shown in Figure 4. Although the Citadel and overlying cellhouse are oriented at an oblique angle to the cardinal directions, herein for convenience we designate "north" as the direction pointing to the left in Figure 4. Thus, with reference to the cellhouse floor plan (Figure 2), north also points to the left such that, naturally, Sunrise Alley is on the eastern side and Sunset Strip is on the western side. Additionally shown in Figure 4 are the locations of the radar profiles (B-scans) mentioned in the text, labeled by the appropriate figure number in which they appear.

A rendering of the Citadel structure along with the cistern additions areas is shown in Figure 5. Marked on the figure are some of the principal targets identified in radargrams as well as the South ABC-blocks radar coverage area. In the next sections of the paper, GPR interpretations from the various Citadel-related radar coverage areas are provided.

Depth slices, along with an interpreted B-scan along Sunrise Alley, are shown in Figure 6a. The radar signatures of two slender ceiling beams extending across the width of the surveyed area are easily seen in the depth slices (Figure 6a, top), with a third one truncated by the stairs to the dungeon. In the B-scan (Figure 6a, bottom), the three beams disrupt the flat-lying reflector at $1.5 \mathrm{~m}$ depth, caused by the ceiling of the underlying SE bastion of the Citadel. The bastion was designed to defend against intruders coming down the adjacent stairs into the dungeon. The large, complex hyperbolic reflectors disrupting the floor reflector at $2.7 \mathrm{~m}$ (apparent) depth are likely caused by two unusually shaped arched columns (Figure 6b) located inside the bastion. The height of the room, from floor 
to ceiling, is apparently only $1.2 \mathrm{~m}$, but it must be remembered that the floor reflector will be "pulled up" relative to the ceiling reflector since the electromagnetic wave velocity in air $(\sim 0.3 \mathrm{~m} / \mathrm{ns})$ is higher than the value $(0.1 \mathrm{~m} / \mathrm{ns})$ used to achieve the B-scan time-to-depth conversion. The velocity pull-up phenomenon is described in [24].

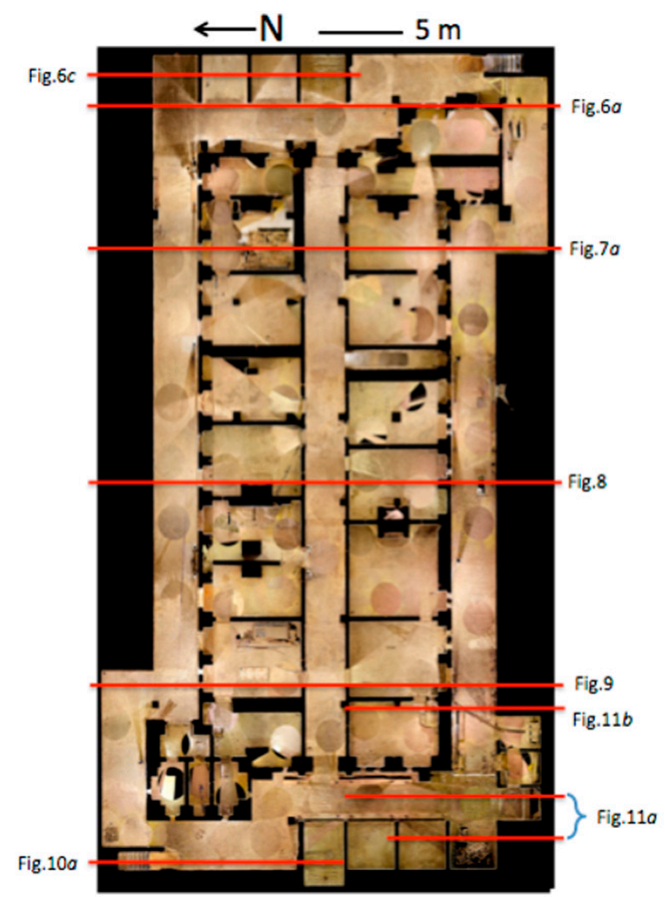

Figure 4. Lidar data (credit: Paul Davidson, NPS; hereinafter P.D.) of 2016 Citadel floor overlain by radar profiles described in the text.

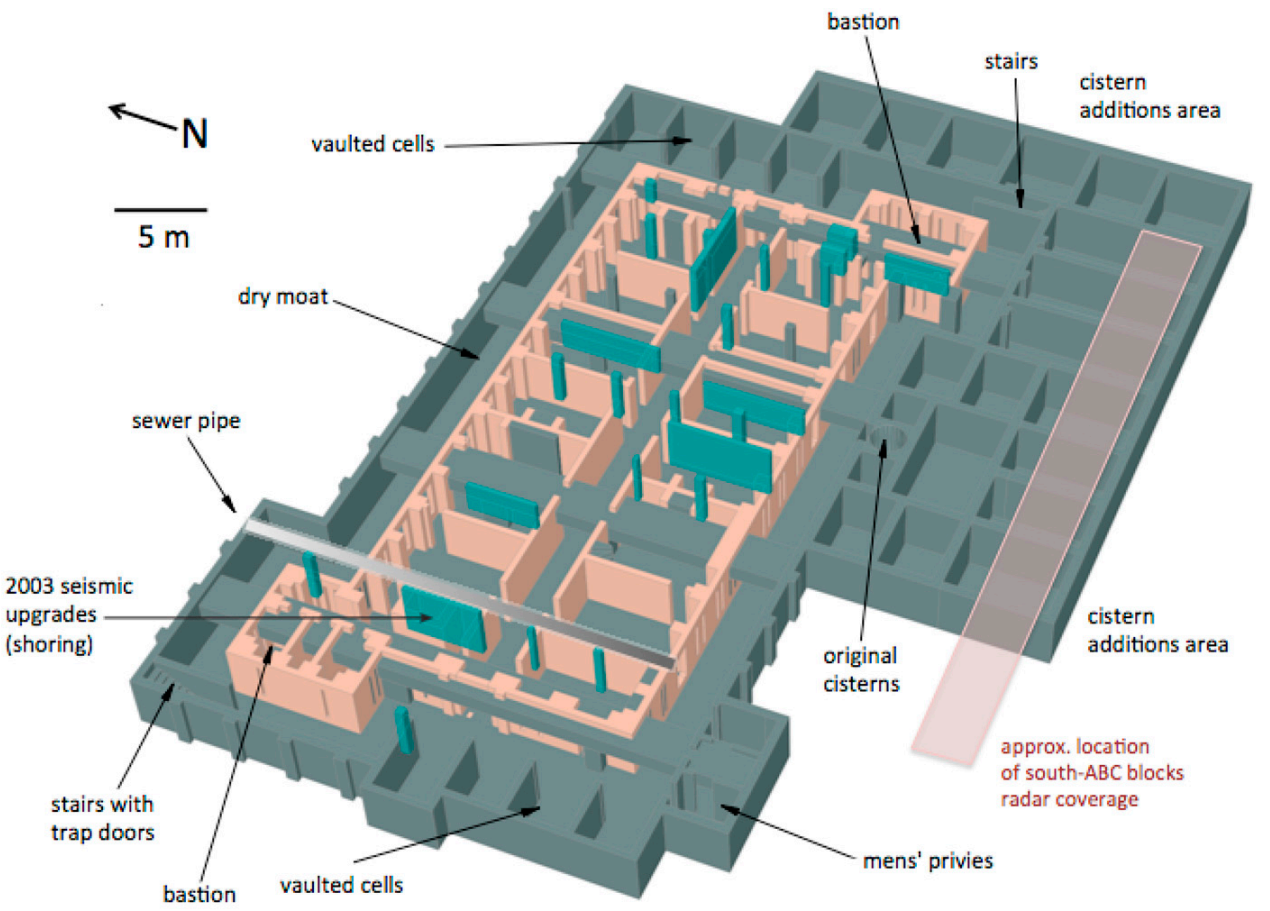

Figure 5. Rendering of the Citadel with the cistern additions area, from [21]. Some of the principal features mentioned in the text are marked, as is location of South ABC-blocks radar coverage area.

At the far right of the Sunrise Alley B-scan (Figure 6a, bottom), the small hyperbolic event may be due to a reflection from a structure associated with the late-19th-century 
"cistern additions" (see Figure 5). This area, now inaccessible and hence without ground truth, was used to store water since the island has no natural water resources. At the left of the depth slices is the location of a series of "dungeon cells" (later these became storage rooms) with vaulted ceilings. The radar profile at $y=0.0 \mathrm{~m}$ in Figure $6 \mathrm{a}$, bottom, does not pass directly over the vaulted cells, but rather over the corridor in front of them, which explains why they do not exhibit a radar signature.

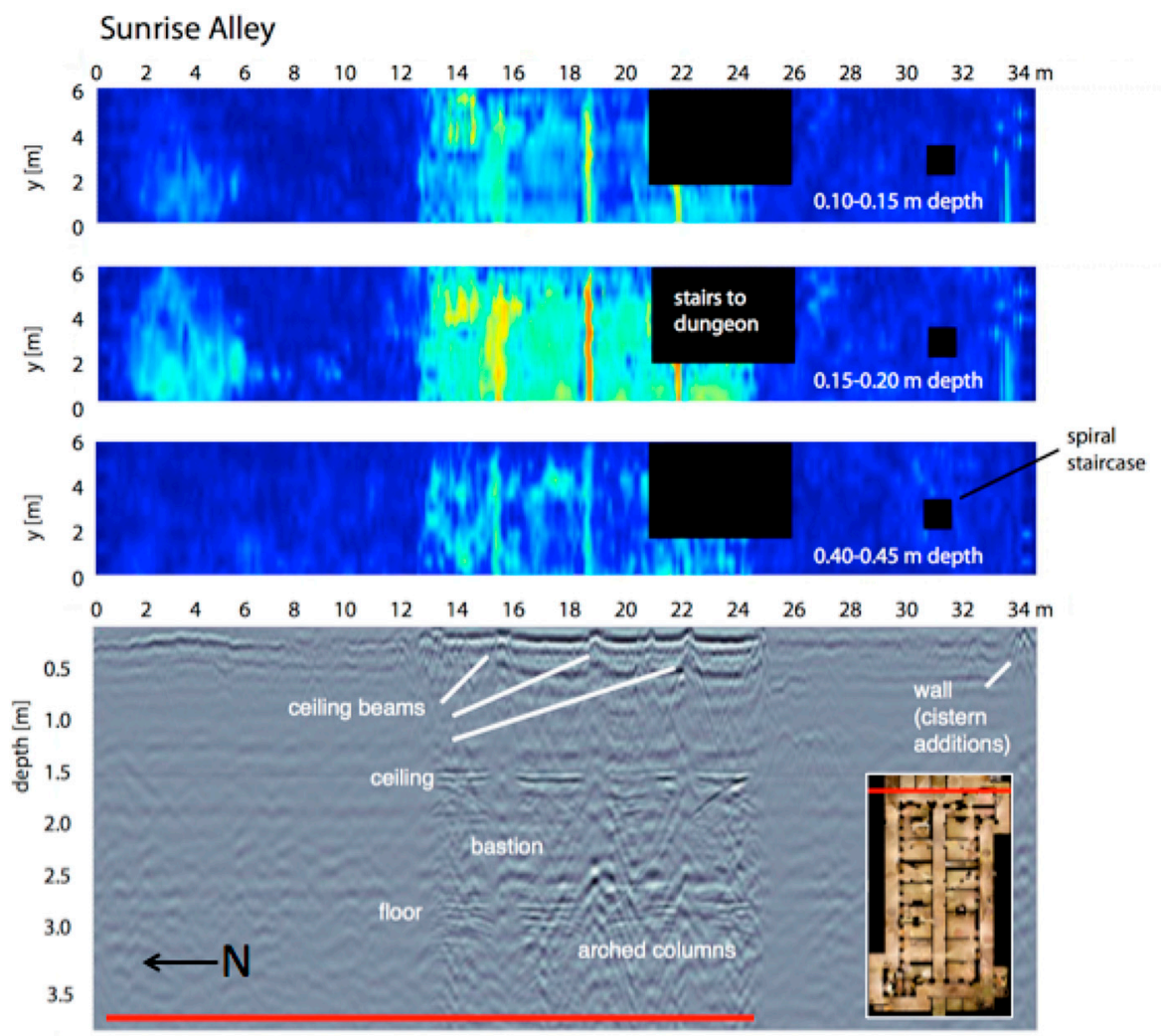

(a)

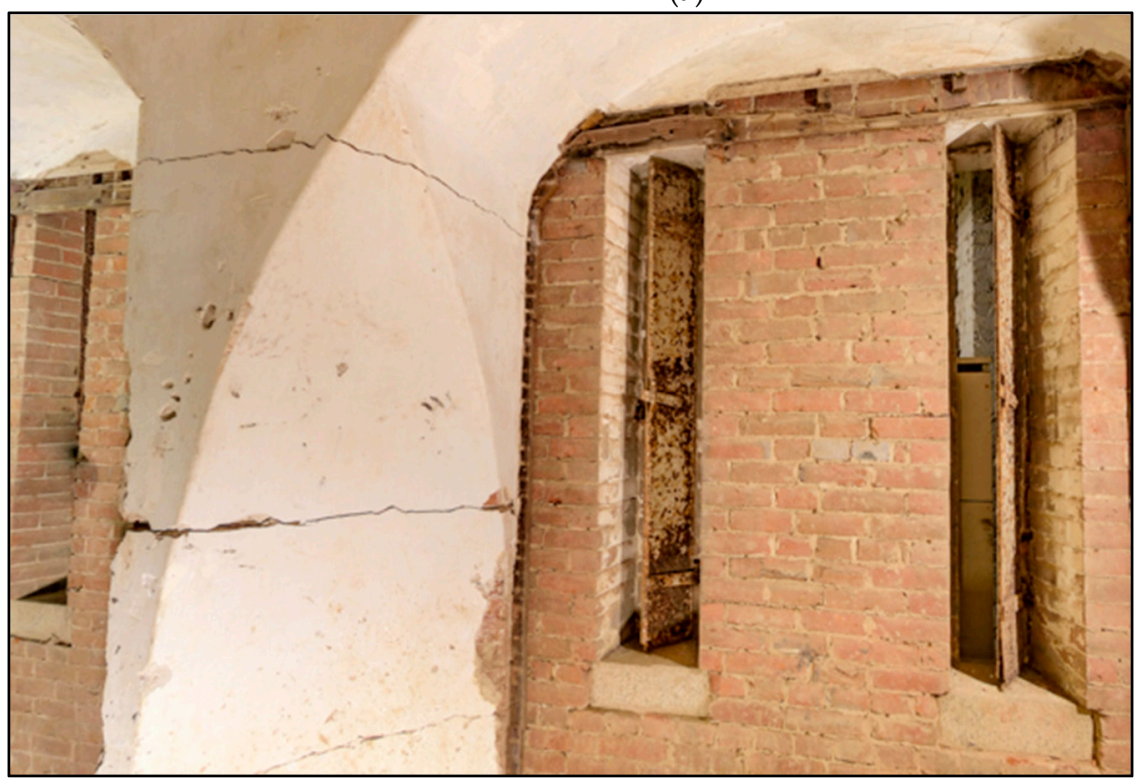

(b)

Figure 6. Cont. 


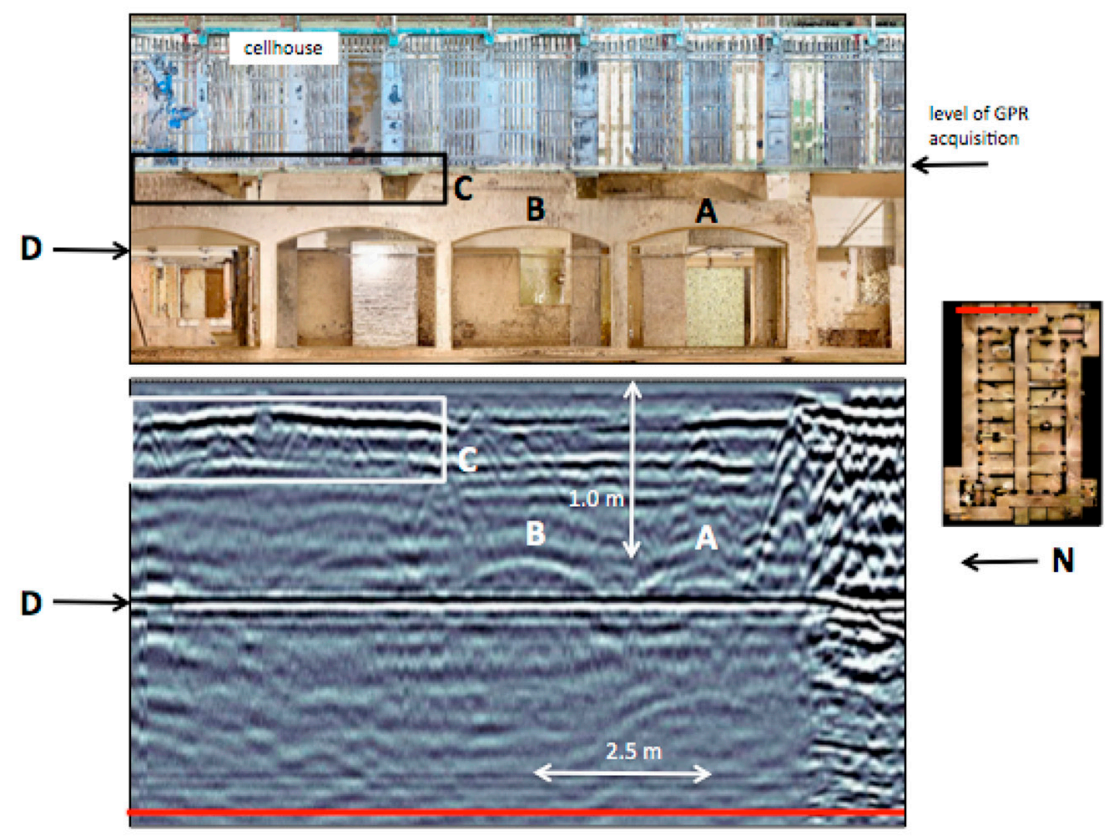

(c)

Figure 6. (a) top: GPR depth-slices and bottom: an interpreted representative B-scan at Sunrise Alley. The B-scan corresponds to $y=0.0 \mathrm{~m}$. The location of the B-scan relative to the Citadel is indicated by the red lines in the insert lidar map and at the bottom of the B-scan. (b) Lidar image (credit: P.D.) of one of the arched columns inside the bastion beneath Sunrise Alley; also shown are gun-slit windows for defense of the Citadel. (c) top: Lidar data (credit: P.D.) at Sunrise Alley showing vaulted ceilings of the former dungeon cells below the cellhouse floor at Sunrise Alley. bottom: B-scan at $y=5.5 \mathrm{~m}$ spanning $x=0.0$ to $x=14 \mathrm{~m}$.

However, in another Sunrise Alley partial B-scan at $y=3.5 \mathrm{~m}$ (Figure $6 \mathrm{c}$, bottom), hyperbolic radar signatures of two of the vaulted ceilings are indeed apparent, they are marked as A,B. The signatures are relatively faint since the electromagnetic wave has to pass through a thick section of masonry between the cellhouse floor to reach the top of the vaulted structure. The apices of the hyperbolae are located at the correct depth of $1.0 \mathrm{~m}$, and are spaced by the requisite $2.5 \mathrm{~m}$. The vaulted structures themselves may be seen in the lidar data (Figure 6c, top). Possible signatures of the other two vaulted ceilings are hinted at in the B-scan, faint hyperbola appear immediately beneath the shallow reflector at $\mathrm{C}$, below which electromagnetic signal does not penetrate effectively. The cause of reflector $C$ is not known, but it could be associated with a metal pipe, or alternatively, construction material within or just below the cellhouse floor, such as steel plate, acting as an excellent radar reflector. Reverberations caused by the floor material of the cellhouse in this location could explain why the tops of the vaulted ceilings appear to be pulled up beneath reflector C. The prominent horizontal event D in the B-scan is unexpectedly strong, but in good alignment with the bottom of the ceiling beam, as shown in the lidar image.

Depth slices, along with an interpreted B-scan along Michigan Ave, are shown in Figure 7a. Radar signatures of at least four steel beams in the ceiling of the prison "shower room" may be seen at the left side of the B-scan and on both depth slices. The shower room, open to visitors, occupies the same level as the Citadel basement (for the floorplan) [25]. The two areas, however, are not connected but rather separated by a 6-m wide zone bereft of radar reflectors which is herein interpreted as the undisturbed bedrock, specifically called "Alcatraz terrane". Geologically, the bedrock is an early Cretaceous graywacke sandstone associated with the subduction of the ancient Farallon plate beneath North America [26]. 
Michigan Ave.
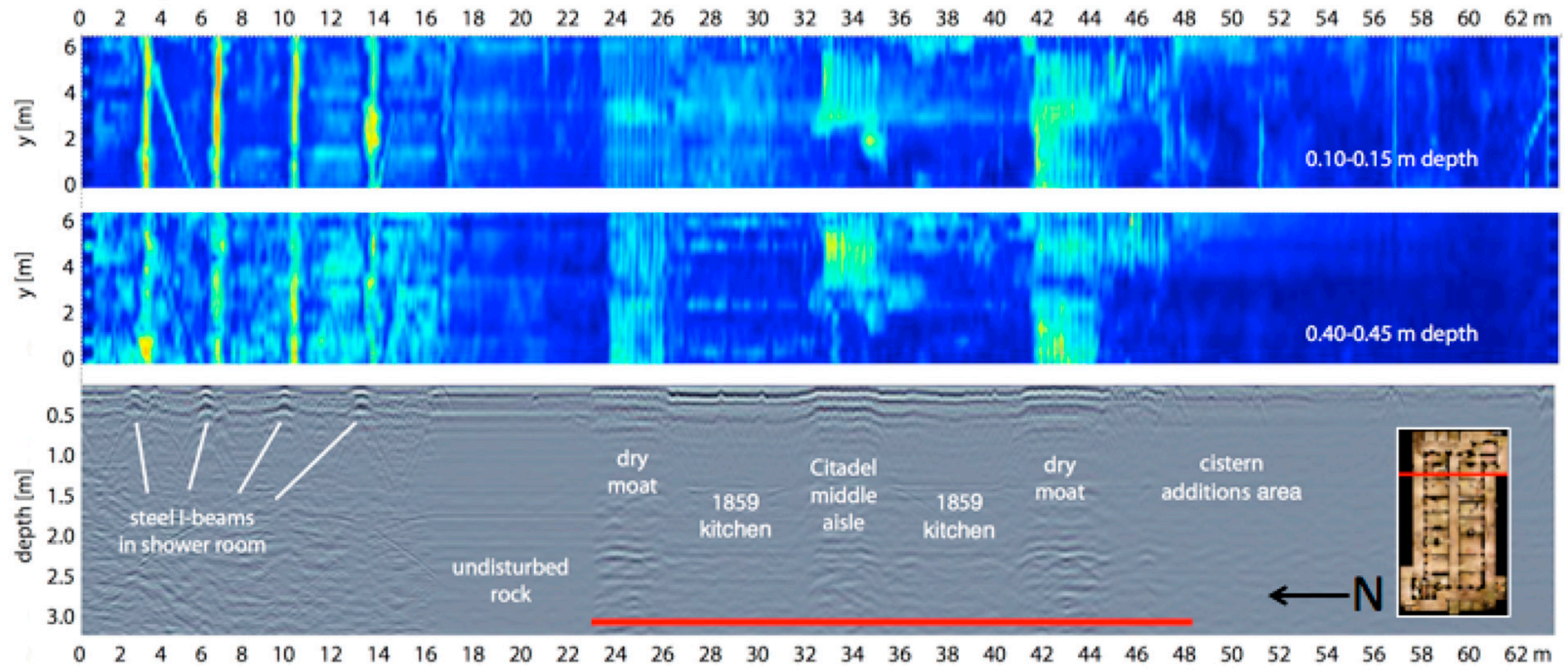

(a)
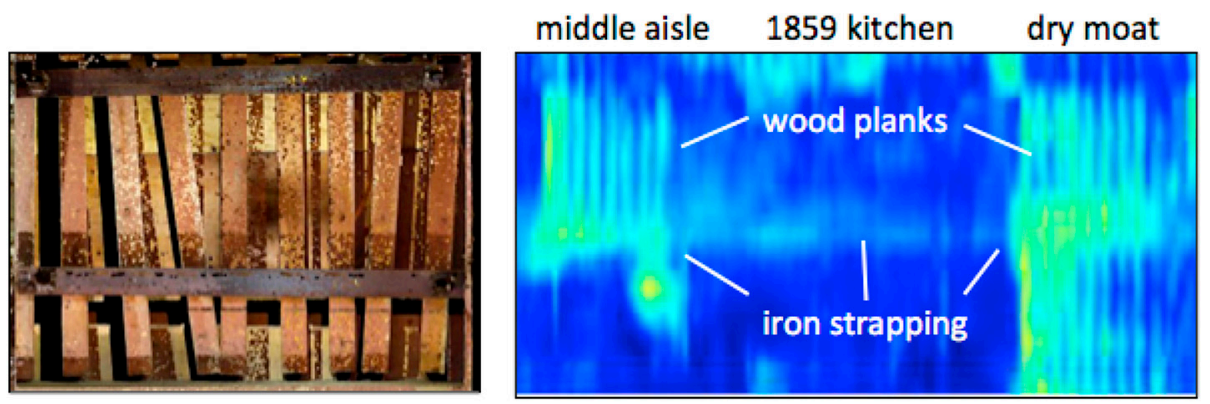

(b)

Figure 7. (a) top: GPR depth-slices. bottom: an interpreted representative B-scan at Michigan Ave. The B-scan corresponds to $y=3.5 \mathrm{~m}$. The location of the B-scan relative to the Citadel is indicated by the red lines in the insert lidar map and at the bottom of the B-scan. (b) left: Lidar data (credit: P.D.) of a ceiling section showing wood planks and iron strapping. right: section of Michigan Ave. depth slice at $x=32-44 \mathrm{~m}$ spanning depth range $z=0.10-0.15 \mathrm{~m}$.

At the right of the Michigan Ave. B-scan resides the cistern additions area wherein several small, shallow hyperbolic reflectors are found; these could mark structures that partition the water storage area, or they may be caused by objects such as pipes or taps related to the water supply. Their signature is also seen in the shallowest $(0.10-0.15 \mathrm{~m})$ depth slice. The Citadel itself lies at the center of the Michigan Ave. radar profiles. The "dry moat" that surrounds the Citadel outer walls, as well as the "middle aisle" of the structure itself, are easily discerned in both the depth slices and the B-scan. The middle aisle is labeled "Hall. Officers Quarters" and the rooms in between are labeled "Kitchens" or "Store-rooms" on the 1859 drawing [27].

The distinctive fine-scale lineations, evident in the depth slices, are caused by wood planks that have been placed in the ceiling above the middle aisle and the dry moat of the citadel. A section of the ceiling exposing the wood planks is shown in the lidar data of Figure $7 \mathrm{~b}$, left. The radar signature of the iron strapping holding the wooden planks in place is also evident; in the GPR depth-slice (Figure 7b, right), the strapping appears to span across the 1859 kitchen, between the aisle and the moat. Note that the area of fine-scale lineations on the depth slices extends to the region $x \sim 45-47 \mathrm{~m}$; these "extra wood planks" occur because the dry moat beneath this radar profile projects around the SE bastion (see Figure 4). GPR non-destructive imaging of wood structures is becoming important in cultural heritage investigations [28] as well as forestry and agriculture applications [29,30]. 
Depth slices, along with an interpreted B-scan along Broadway, are shown in Figure 8. The GPR response is very similar to that of Michigan Ave. The similarity is expected as the lidar data, historical documents, architectural drawings, and also direct observations inside the Citadel show that the radar profiles pass over the same structures, namely the shower room, the undisturbed Alcatraz terrane, the dry moat, the Citadel structure and the cistern additions area. The knowledge that similar ground-truth generates similar radar signatures is important to keep in mind when working at cultural heritage sites where only partial ground-truth is available. It means that radar-signature interpretations from ground-truthed areas can be extrapolated into non-ground-truthed areas that exhibit analogous radar signatures.
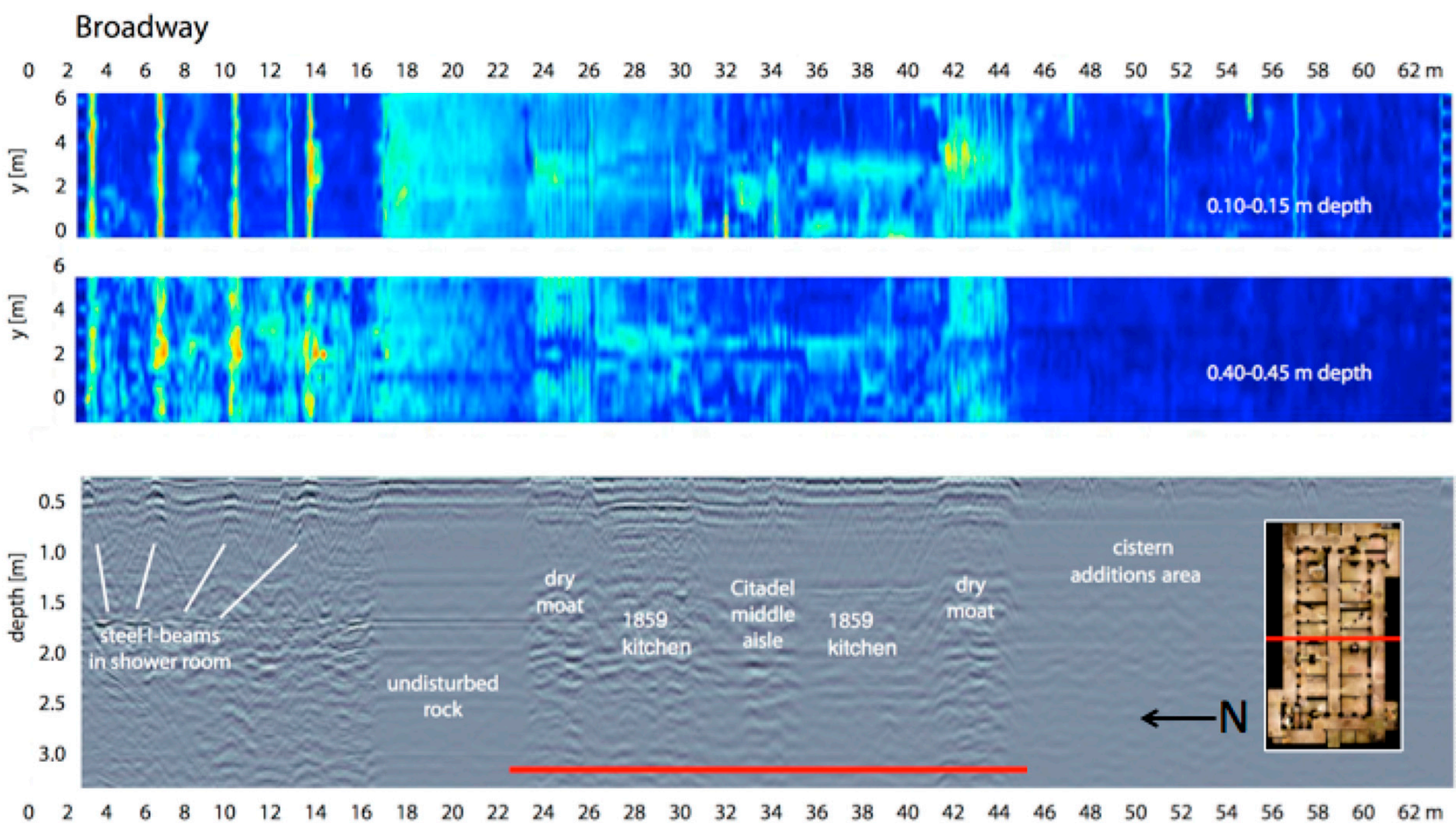

Figure 8. GPR time-slices and interpreted representative B-scan at Broadway. The B-scan corresponds to $y=3.5 \mathrm{~m}$. The location of the B-scan relative to the Citadel is indicated by the red lines in the insert lidar map and at the bottom of the B-scan.

The depth slices from Park Ave. are similar to those of Broadway and Michigan Ave. and hence are not shown here. However, note that the representative Park Ave. B-scan (Figure 9, bottom) has a narrower region of undisturbed Alcatraz terrane rock and a wider (double) zone of moat than the profiles previously discussed. This is because the dry moat projects outward around the NW bastion of the Citadel (see Figure 4). The B-scan also provides important information about the determination of the heights of underground structures. A N-S architectural cross-section [25], spanning the shower room to the Citadel, is shown in Figure 9, top. From this cross-section, it is evident that the ceilings of the shower room and the Citadel are at the same elevation. However, the height of the shower room is $\sim 3.0 \mathrm{~m}$ while that of the Citadel is smaller, at $\sim 2.4 \mathrm{~m}$. Thus, the floor of the Citadel is at a higher elevation than the floor of the shower room.

The floors of the shower room and the Citadel show up as prominent flat-lying reflectors in the Park Ave. B-scan (Figure 9, bottom). The Citadel floor reflector appears at a two-way travel time of $27 \mathrm{~ns}$, while the shower-room floor reflector appears later at 34 ns. Given the known heights of the two rooms from the architectural cross-section, these travel-time values are consistent with a $1.0-\mathrm{m}$ thick ceiling of radar velocity $0.1 \mathrm{~m} / \mathrm{ns}$ in the shower room, and a $0.8 \mathrm{~m}$ thick ceiling of velocity $0.1 \mathrm{~m} / \mathrm{ns}$ in the Citadel; values that seem reasonable from the perspective of masonry and concrete construction materials 
and techniques [31]. There is of course a tradeoff between ceiling thickness and material velocity that could yield the same two-way travel time of a floor reflector for different combinations of these parameters. Specifically, the elementary principle applies to the travel time $t$ being equal to the quotient of material thickness $d$ and material velocity $v$, such that $t=d / v$.

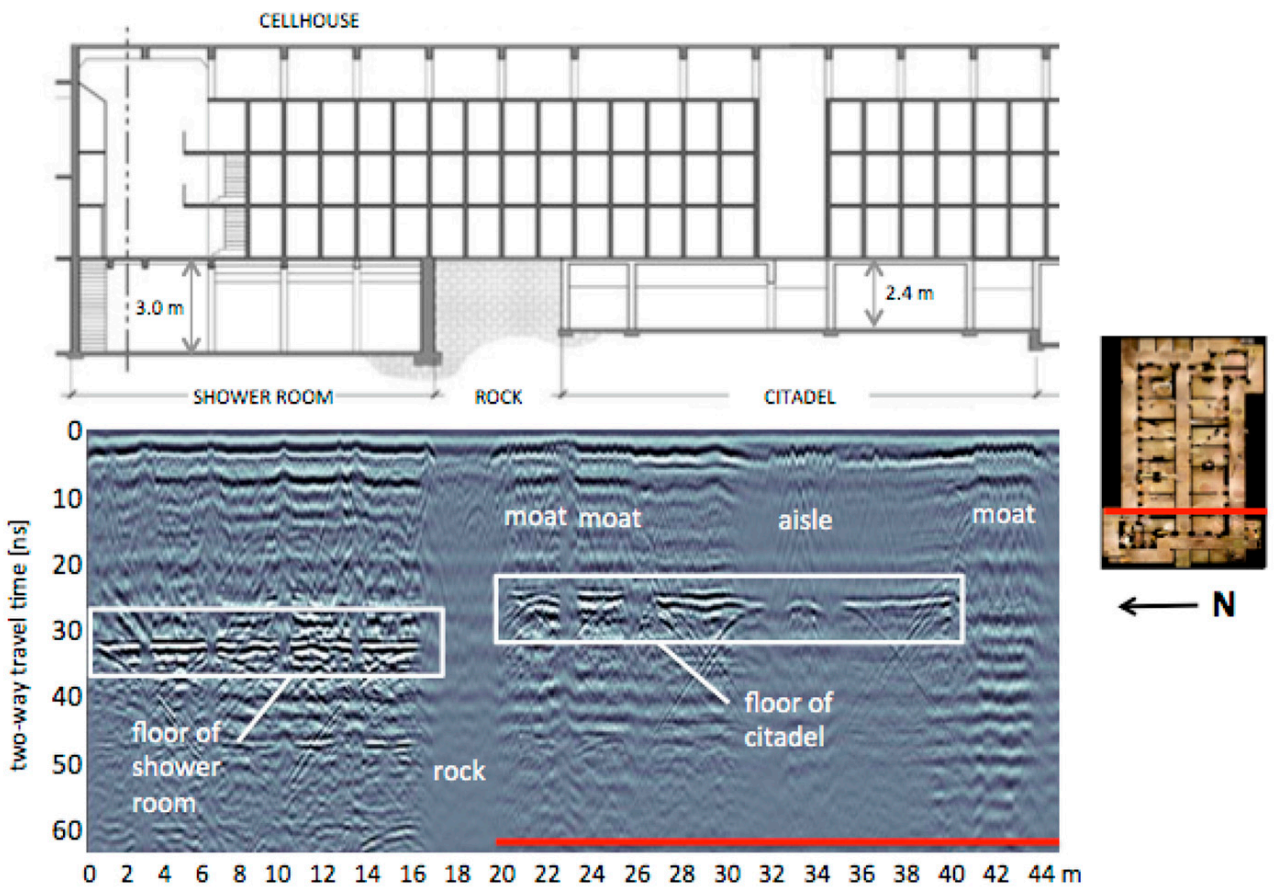

Figure 9. top: Architectural N-S cross-section of shower room and Citadel, modified from [25]; bottom: partial B-scan from Park Ave.

Depth slices, along with an interpreted B-scan along Sunset Strip, are shown in Figure 10a. At the left side of the depth slices, ceiling beams associated with the "clothing issue room" at the west end of the shower room are evident. A flat-lying reflector, corresponding to the floor of this room, is also seen at 32 ns of two-way travel time in the B-scan. The reflector marked A in the B-scan may be caused by a laundry table in the clothing issue room. The section of undisturbed Alcatraz terrane rock between the clothing issue room and the Citadel appears, as usual, without significant internal radar reflections. In strong contrast is the dramatic radar signature of the metal trap doors, and underlying air space, at the top of the stairs leading down to the Citadel. The metal doors, shown in Figure 10b, left, were closed shut at the time of the GPR survey. The radar profile that generated the B-scan passed over the edge of the closed trap doors, along the red line shown in the figure. Strong reflections, diffractions and reverberations are evident in the B-scan. The flat-laying series of reflectors at two-way travel time $20-27$ ns in Figure 10b, right, are likely caused by the underside of the trap doors. Note that the radar signature beneath these reflectors tends to be less well-resolved but is otherwise a geometric copy of the radar signature above them, indicating reverberations of the electromagnetic signal between the upper and lower surfaces of the metal comprising the trap door. A smooth metal surface is an excellent reflector of radar signals [32]. Finally at Sunset Strip, evident at the right-side of the depth slices and the B-scan (Figure 10a), are ceiling beams spanning the dry moat of the Citadel. 

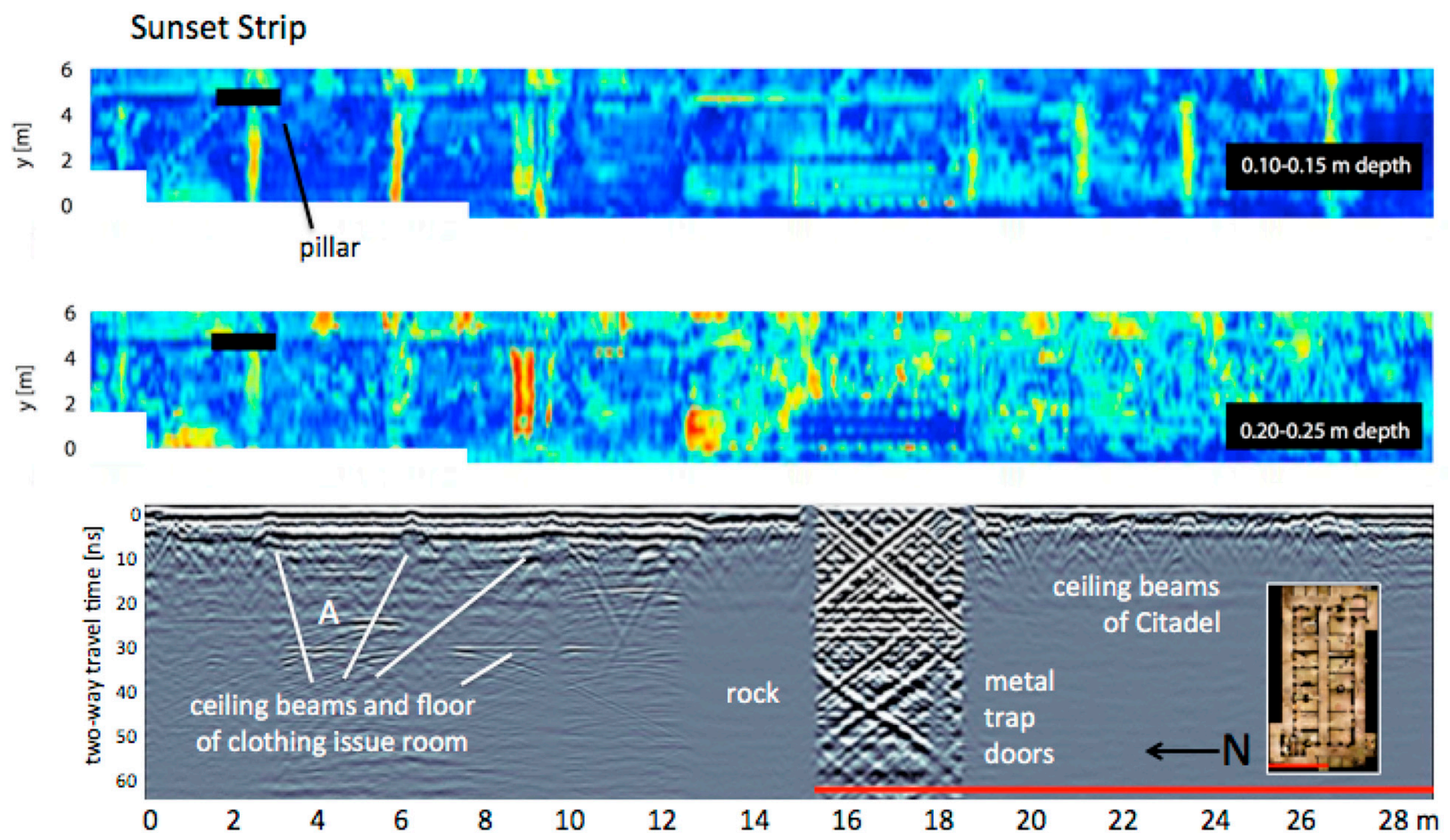

(a)

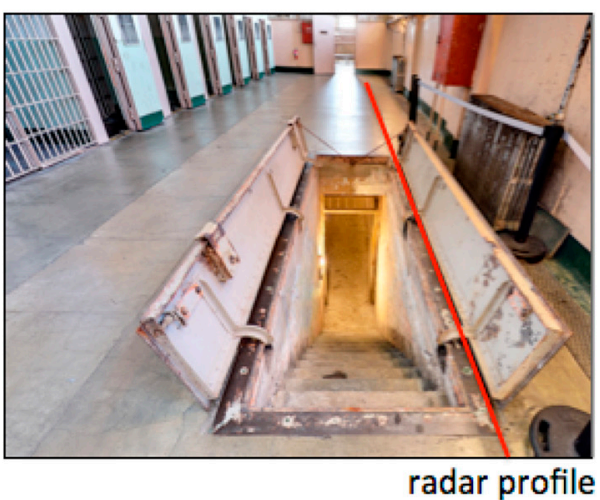

metal trap doors

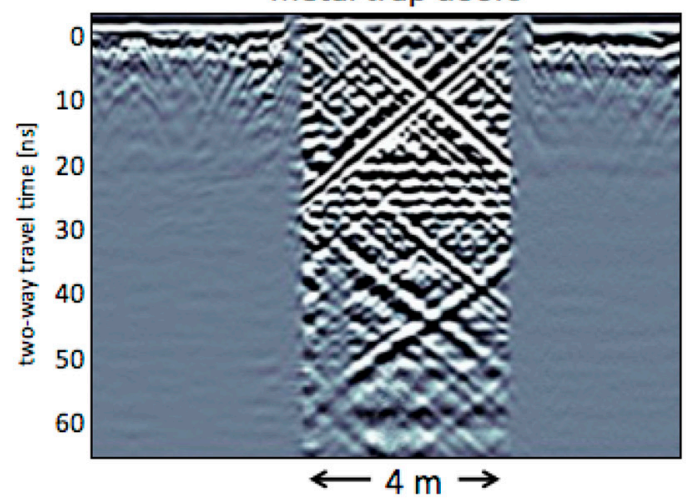

(b)

Figure 10. (a) GPR time-slices and interpreted representative B-scan at Sunset Strip. The B-scan corresponds to $y=0.5 \mathrm{~m}$. The location of the B-scan relative to the Citadel is indicated by the red lines in the insert lidar map and at the bottom of the B-scan. (b) left: Lidar image (credit: P.D.) of metal trap doors in cell block D (Sunset Strip) leading down to the dungeon, with radar profile shown, right: detail of GPR B-scan along the radar profile shown at left.

Depth slices, along with two interpreted B-scans acquired in the Library, are shown in Figure 11a. The library overlies the SW corner of the Citadel comprising the dry moat, several dungeon cells with vaulted ceilings, and three smaller rooms marked "Men's Privy" on the 1859 drawing [27] (see also Figure 5). The fine-scale lineations, parallel to the $y$-axis, seen most clearly in the two shallowest depth slices (Figure 11a, upper left), correspond to wood planks in the ceiling of the dry moat. The planks show up as the near-surface zig-zag reflectors in the B-scans at Figure 11a. The B-scan at the left also shows the hyperbolic signatures of the vaulted ceilings of the dungeon cells (compare with the same features in the Sunrise Alley B-scan of Figure 6b, bottom), although these signatures are not apparent in the depth slices. 

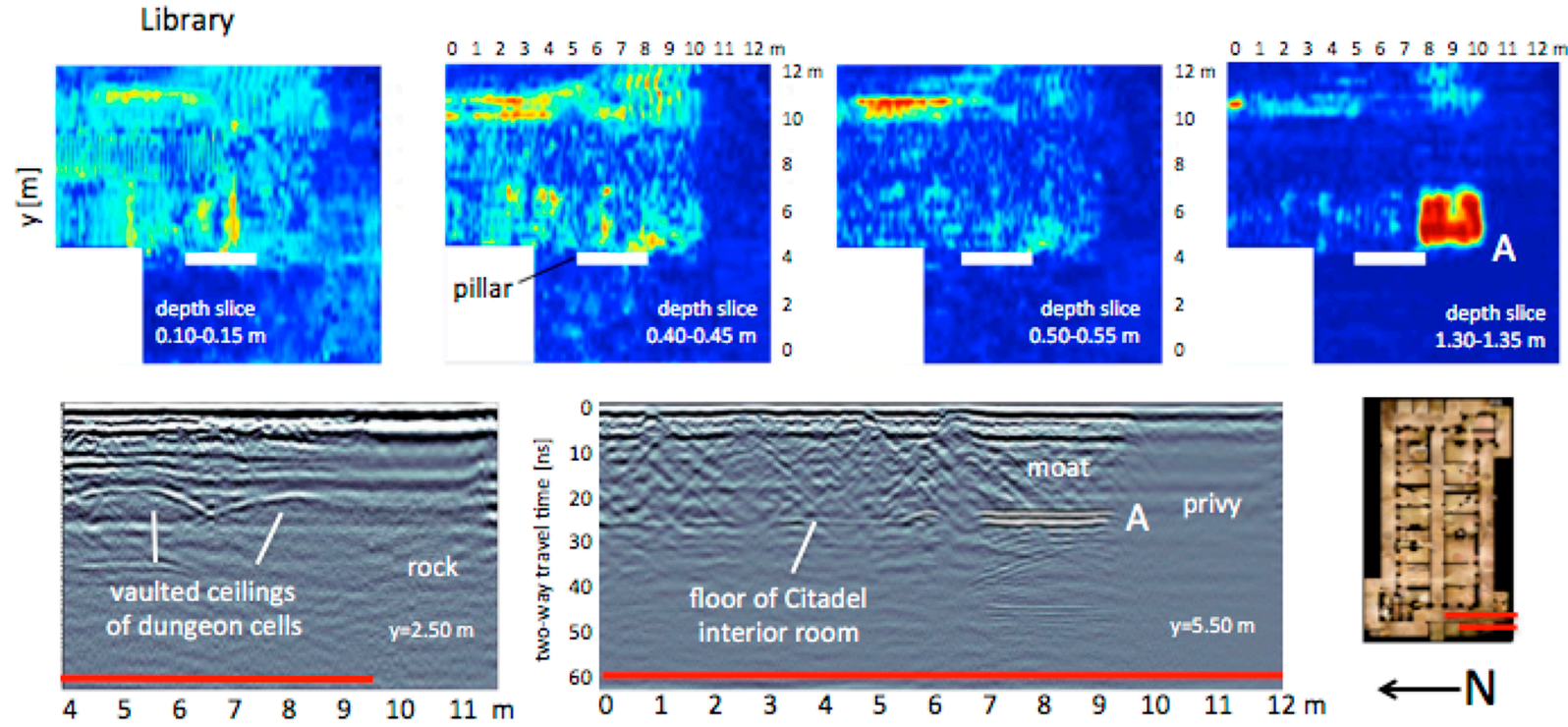

(a)
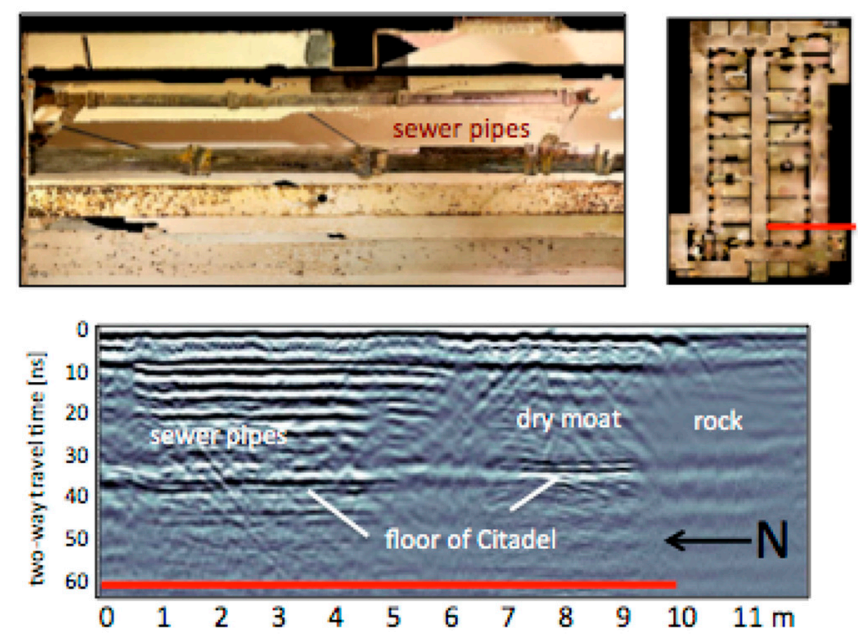

(b)

Figure 11. (a) GPR time-slices and representative B-scans at Library. The B-scans corresponds to $y=2.5 \mathrm{~m}$ (bottom left) and $y=5.5 \mathrm{~m}$ (bottom right). The location of the B-scans relative to the Citadel is indicated by the red lines in the insert lidar map which correspond to the red lines at the bottom of the B-scans. (b) top: Lidar data (credit: P.D.) of the ceiling of the Citadel showing an exposed section of sewer pipes; bottom: B-scan at Library showing sewer-pipe signatures. The B-scan corresponds to $y=10.5 \mathrm{~m}$ on the depth-slices of the previous figure. The location of the B-scan relative to the Citadel is indicated by the red line in the insert lidar map which coincides with the red line at the bottom of the B-scan.

The other B-scan in Figure 11a (bottom right) includes a very strong reflector labeled A at $\sim 25 \mathrm{~ns}$ two-way travel time. This reflector lies at or near the base of the dry moat, but it is much stronger than a typical reflector from the floor of the moat. It is unclear why there is such a strong reflector in this part of the moat, although it might be related to the historic sewage disposal system. This supposition requires further investigation, but it is known from historical documents that the sewage from the cellhouse was directed via a pipe into a tunnel at the base of the easternmost privy, which is located at the right-side of the B-scan. From there, the sewage was discharged into San Francisco bay. Note that the privy itself is not imaged in the B-scan, perhaps because of its thick masonry ceiling. The privies, like the vaulted cells, lie outside the main Citadel structure (see Figure 5) and extra ceiling reinforcement was probably installed for defensive purposes. 
Another B-scan from the Library is shown in Figure 11b, bottom. It contains a strong near-surface sequence of reflectors. These reflectors are aligned with a pair of iron pipes that are evident in lidar scans of the ceilings of interior rooms of the Citadel (the pipes are shown in Figure 11b, top). The larger of the pipes appears to be connected to the pipe that is presently found on the easternmost privy floor. The pipe can be seen in Figure 4, cutting diagonally across the moat.

Depth slices, along with two interpreted B-scans acquired at South ABC-blocks, are shown in Figure 12. Most of the radar coverage passes over the cistern additions area, as indicated in Figure 5, except for several meters on the western side. The original cisterns were built to provide water for the island staff and prisoners, but these proved inadequate and an additional area to house additional cisterns had been established by the late 19th century [21]. There is no ground-truth available beneath the south-ABC blocks radar coverage area.

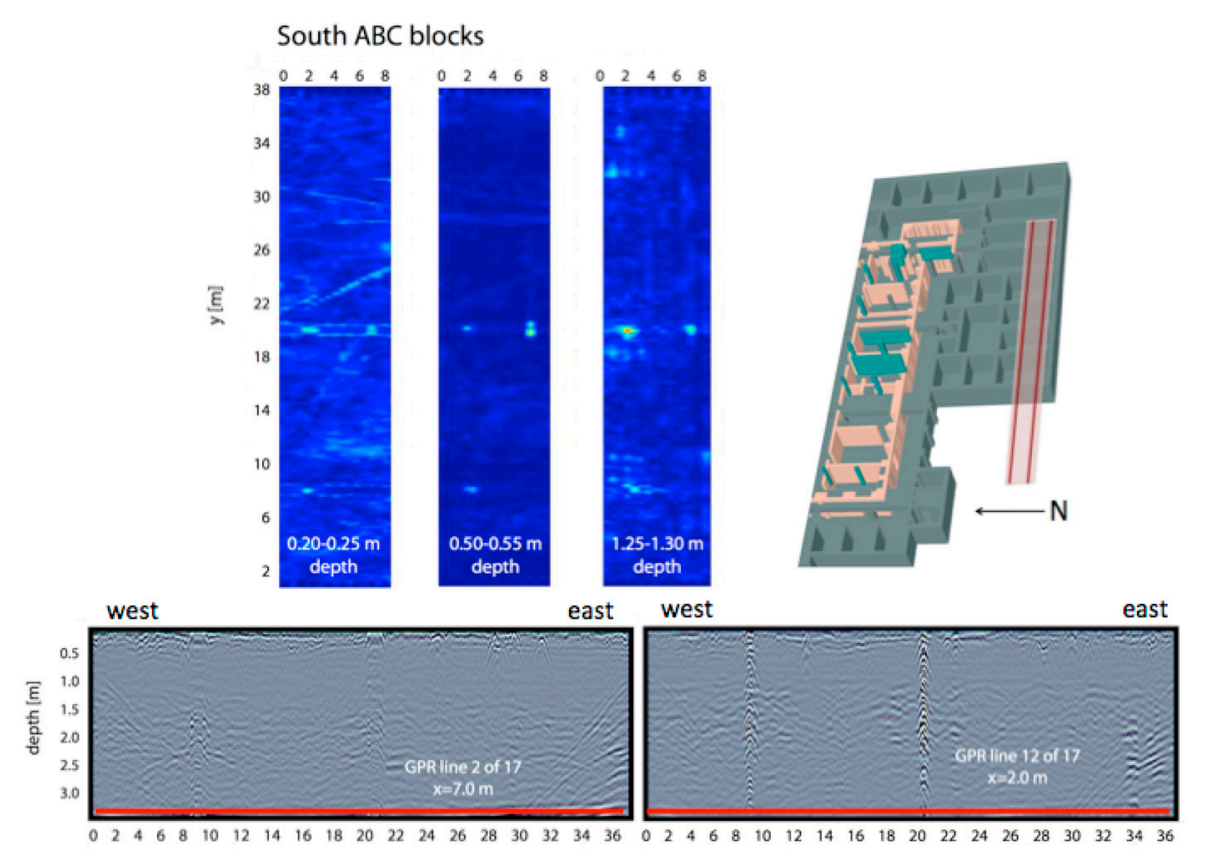

Figure 12. GPR depth-slices and representative B-scans at South ABC-blocks. The red lines at the bottom of the B-scans correspond to the red lines in the rendering at top right.

The depth slices in Figure 12, top, show a prominent linear N-S anomaly stretching across the width of the coverage area at location $y \sim 20 \mathrm{~m}$, along with a fainter one at $y \sim 8 \mathrm{~m}$. The signature of their causative structures is evident in the B-scans along the lines $x=7.0 \mathrm{~m}$ and $x=2.0 \mathrm{~m}$ at Figure 12, bottom. Specifically, the B-scans show two vertical linear sequences of strong hyperbolic reflectors, extending the entire depth range. These signatures are characteristic of multiple reverberations, or "ringing", from a narrow metal reflector. Such a signal could be caused, for example, by a metal cover placed over a roof entry point into one of the cistern-area chambers; this manner of entry into the chambers is suggested on the 1859 drawing [27]. The signals appear too strong to be caused by a less reflective cover material such as wood, brick or masonry, or an open hole. The linear anomalies in the depth slices are elongated and straight; these could be caused by some type of structure that provided access to entry points in the roofs of the chambers. The entry points themselves would correspond to the "bright spots" on the depth slices.

The rendering in Figure 5 also suggests that 5 or 6 cistern chambers should be evident in the South ABC-blocks coverage area. A closer examination of the B-scans Figure 12, bottom, shows that other near-surface hyperbolic reflectors are indeed present, although none of them generate a vertical sequence of strong reflectors. There also appears to be a number of broad-scale (width, $\Delta x \sim 3-4 \mathrm{~m}$ ) faint hyperbolic reflectors at depth $\sim 1 \mathrm{~m}$, especially in the 
B-scan at the lower right. Whether or not these faint reflectors are associated with actual cistern chamber roofs requires further investigation.

Depth slices from Times Square along the north margin of the cellhouse are shown in Figure 13 (left two panels). Although this area is outside the Citadel footprint, the radar signatures are examined here since they illustrate an important aspect of interpretation that should be of interest to cultural heritage investigators. The Times Square data were acquired along E-W lines running parallel to one of the long ceiling beams in the underlying shower room. The radar signature of the ceiling beam is highlighted by the white rectangles in the left two panels. Note that there are also a number of linear features running N-S beneath Times Square. However, here the focus is on the E-W ceiling beam extending almost the full length of the survey area. In Figure 13 (right panel), the intersecting portions of depth slices from several areas with N-S oriented acquisition lines (Michigan Ave., Broadway and Park Ave.) are shown. The direction of data acquisition in these surveyed areas is perpendicular to the long ceiling beam in the shower room. Notice that the radar signatures of the ceiling beam in these areas are much more distinct than the signature of the same structure from the Times Square acquisition. In general, the radar signature of an elongated target is much more prominent in the case where the acquisition line is oriented perpendicular to the long axis of the target, as opposed to acquisition oriented parallel to the target. This is a well-known GPR polarization phenomenon. The physics underlying GPR polarization phenomena is described in detail by Roberts and Daniels [7]. Note that the ceiling-beam signatures shown in Figure 13 (right panel) are not precisely aligned with each other. Small misalignments such as these are expected, since the GPR antennas and their housings are of finite size and separation, and moreover the acquisition unit is sometimes difficult to precisely maneuver when it is close to walls and other obstructions.
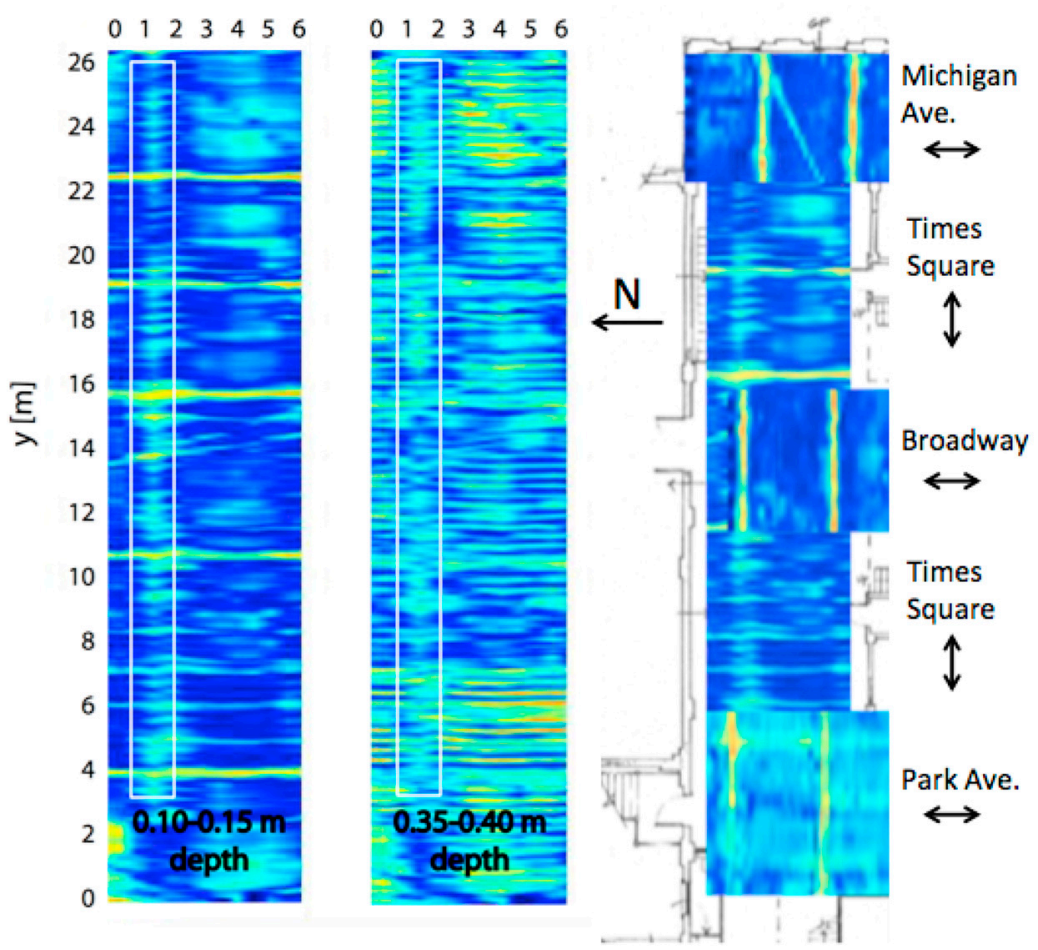

Figure 13. (left two panels) GPR depth-slices from Times Square; (right panel) Times Square depth slices superimposed on intersecting portions of Michigan Ave., Broadway and Park Ave. depth slices. The double-headed arrows show the directions in which the GPR data were acquired.

\section{Discussion}

A composite GPR depth-slice from all 9 surveyed areas is shown in Figure 14. This figure provides a synoptic view of the radar signatures of the subsurface structure beneath the cellhouse, including the Citadel and its dry moat, the Alcatraz terrane, the cistern 
additions area, and the shower room with the adjoining clothing issue room. Clearly, the depth slice is extremely rich in detail and, in this paper, only a first-order interpretation has been made of some of the primarily observed radargram features. The reader will probably observe a number of unexplained features in Figure 14, and different features will become apparent if a different depth range is selected to display. Moreover, a thorough analysis of ground truth and historical documents, not to mention the performance of additional types of non-destructive testing, would yield additional insights beyond those offered in the present paper.

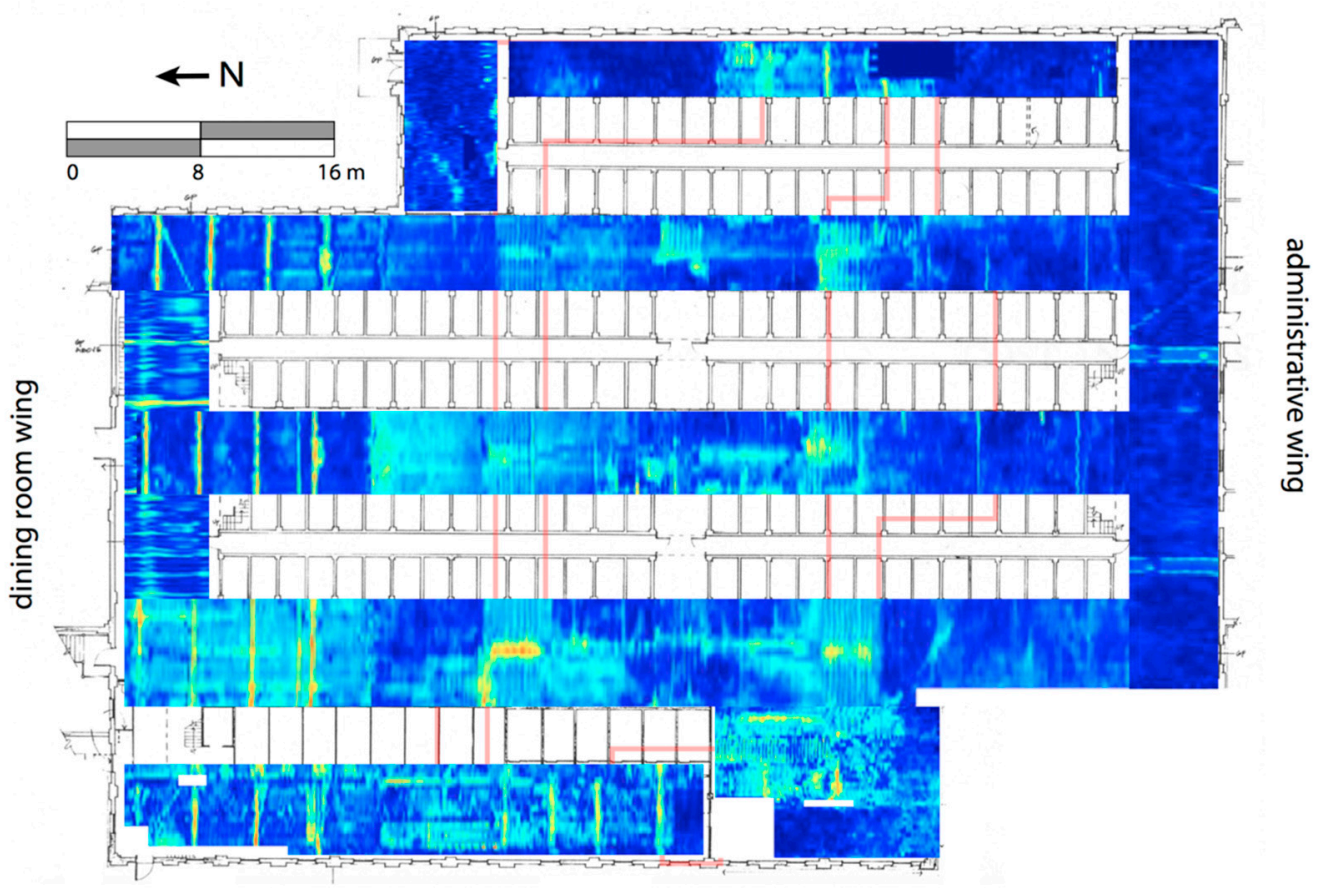

Figure 14. Composite GPR depth-slice spanning 0.10-0.15 m depth.

The complexity of GPR radargrams makes accurate and reliable interpretation a difficult task, especially where there is a lack of knowledge regarding characteristics of the structure under investigation such as the construction techniques used, the architectural plans of the original building and those of later modifications or refurbishments, the building materials involved and their current state of environmental degradation [1]. Advanced GPR processing techniques are definitely useful to practitioners in assisting the interpretation of the causative structures that provoke interesting radar signatures at a given cultural heritage site. This paper has presented only minimally processed time/depth slices and B-scans, and from these a great deal has been learned, but additional processing steps such as spatial-wavenumber filters, velocity analysis, migration and attribute analysis [23], if done carefully, in some cases could help to further resolve actual target structure and reduce contamination from clutter signatures and the effects due to wave propagation. While it is not the intent of the study to demonstrate the benefit of any or all of these useful techniques, an example of advanced processing is shown in the Appendix A, and in the companion paper further analysis of representative B-scans from the Alcatraz citadel is performed using curvelet methods.

The ground truth which underlies the radargram interpretations presented herein comprises mainly the 2016 lidar dataset, in addition to a few key historical documents and architectural drawings. In many cultural heritage investigations, historical information is relied upon as the primary aid to GPR radargram interpretation within subsurface areas that are not directly accessible. This approach was taken for analysis of the GPR data from the cisterns additions area, for example, where lidar is not available. In general, "ground truth" comes in many forms-lidar scans, photographs, stories, drawings, oral 
histories, accidental exhumations, planned excavations, etc. There is a copious reservoir of such information about Alcatraz that we have not tapped into in this study, but which surely contributes to the rich knowledge we have of the Citadel and its significance in the context of history of the American west. The purpose of this study is not to add further insight to the fascinating history of the fortress lying beneath the main prison building at Alcatraz but rather, as mentioned, to serve as a useful reference for ground-penetrating radar interpretation that can be used at other multi-level cultural heritage sites.

Early on in the development of GPR for subsurface investigations, in the field of hydrogeology, Beres and Haeni [33] presented a classification of radar signatures that turned out to be extremely useful for stratigraphic interpretation. Distinctive patterns and textures characterizing an individual radargram, or a portion thereof, were associated with distinctive sedimentological structures such as thin beds, cross-bedded strata, hummocky surfaces, gravel deposits, boulder fields, etc. These patterns and textures later became known as "radar facies" [34,35] in analogy with the "seismic facies" long known from seismic interpretation particularly within the oil and gas exploration industry. Similarly, in this paper we have seen distinct signatures from well-defined targets; the signatures from the wood planks and the vaulted ceilings being two examples of putative "cultural heritage" radar facies (see Figure 15). A classification or compilation of common cultural heritage features, such as these, into a comprehensive facies classification scheme would be a logical extension of the work presented in this paper aiming at the development of a practical guide to field investigations.

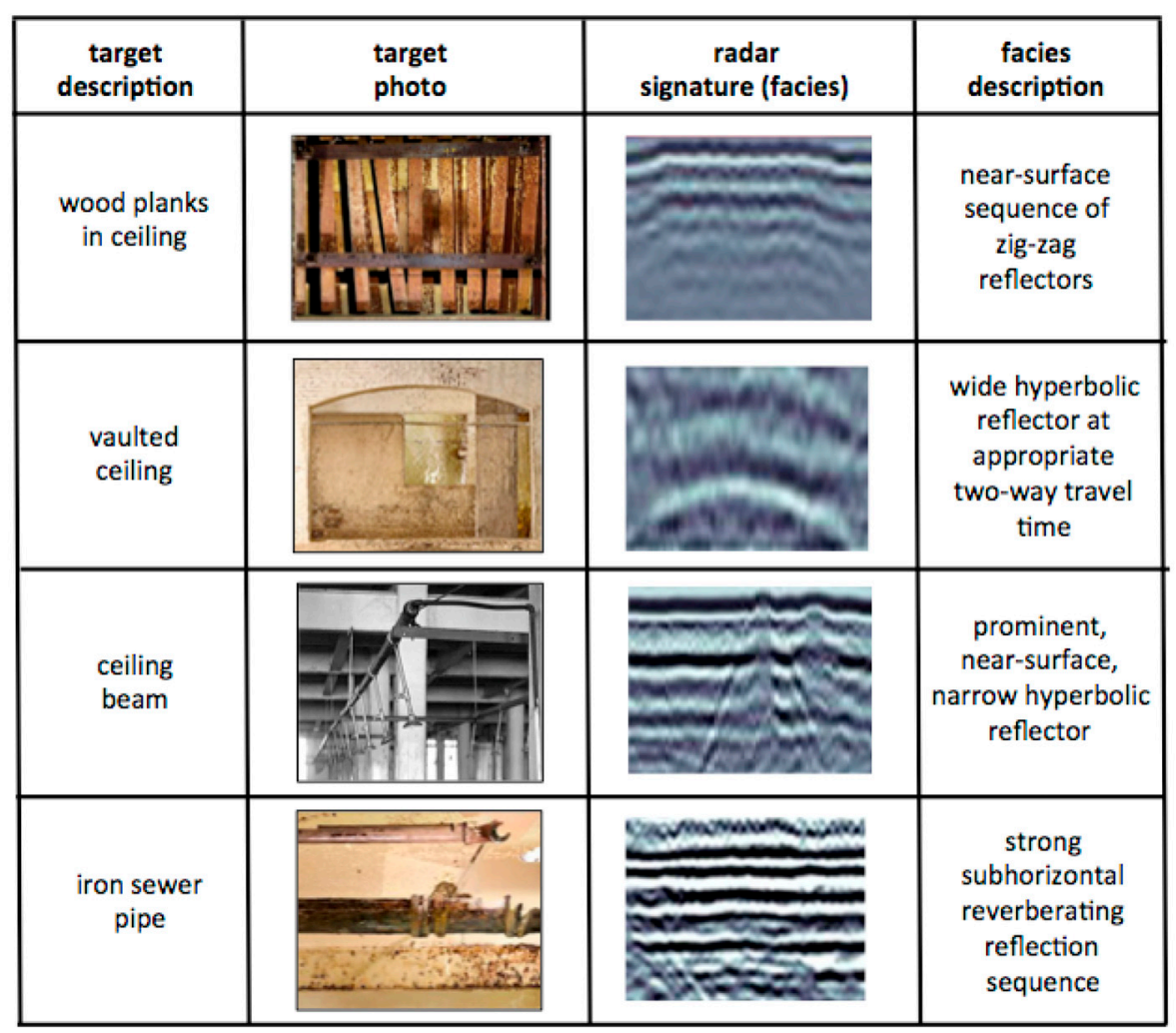

Figure 15. A table of cultural-heritage radar signatures to illustrate the radar facies concept. The photo of ceiling beams in the shower room is from [18].

\section{Conclusions}

GPR is an important non-destructive tool at cultural heritage sites that are characterized by a complex history of construction resulting in multiple levels of structure. Here we have presented the results of a GPR survey of the accessible floor area of the Alcatraz main prison cellhouse, with a focus on the part overlying the historical remnants of the 19th 
century basement of the citadel, the dry moat, and surrounding areas. The interpretation of the radar signatures from the underlying building is complicated by the complexity of electromagnetic wave propagation in the strongly heterogeneous building materials that comprise the multi-level historical fabric. Nevertheless, the GPR investigation, with the aid of the abundant ground truth, identified both modern infrastructure such as sewer pipes and ceiling beams, as well as historic architectural features such as the moat, vaulted ceilings, arched columns, and cisterns. Cultural heritage sites such as this one, for which direct ground verification is available, constitute a valuable testbed that can guide radargram interpretations of similar multi-level structures of historic interest, but where ground truth is sparse or absent. Development of a radar facies classification scheme that is specific to cultural heritage investigations would be a logical extension of this study.

Author Contributions: Conceptualization, R.R.W.; methodology, M.E.E. and T.S.D.; software, M.E.E. and H.R.G.; validation, P.G. and J.H.; formal analysis, M.E.E.; field work, M.E.E., T.S.D. and R.R.W.; resources, R.R.W., P.G. and J.H.; data curation, M.E.E.; writing-original draft preparation, M.E.E.; writing-review and editing, T.S.D., R.R.W., H.A.R.-G., P.G. and J.H.; visualization, M.E.E.; project administration, M.E.E. and R.R.W.; funding acquisition, M.E.E. and R.R.W. All authors have read and agreed to the published version of the manuscript.

Funding: This research was funded in part by Howard Karren Endowed Professorship.

Institutional Review Board Statement: Not applicable.

Informed Consent Statement: Not applicable.

Data Availability Statement: The data used in this study is available upon request from corresponding author.

Acknowledgments: This work was conducted under Archaeological Resources Protection Act permit PWR-1979-14-CA-02 (GOGA). We would like to thank the National Park Service staff for their assistance and patience while we conducted the fieldwork; as well as Tanya Komas and the students from the Concrete Industry Management field school, California State University Chico, who helped with data acquisition.

Conflicts of Interest: The authors declare no conflict of interest.

\section{Appendix A}

The B-scan radargrams shown throughout this paper have been minimally processed with the only steps being background subtraction, de-wow and SEC gain. A wide range of more advanced data processing options are generally available to the GPR interpreter [23]. These options include horizontal and vertical filters, migration, and display of signal attributes such as instantaneous frequency and instantaneous phase. For details see [23]. It should be noted however that a portion of the original information contained in the raw radar signal is always lost at each processing step, so care must be taken not to reduce the interpretability of a radargram by over-processing. An example of the instantaneous frequency attribute of a radargram from the Alcatraz Citadel that has been migrated using velocity $0.2 \mathrm{~m} / \mathrm{ns}$, and displayed using a popular "seismic-style" color map, is shown in Figure A1, right. While the "further-processed" attribute display does contain interpretable information and many of the diffractions have been removed by the migration process, arguably the more "primitive" radargram at Figure A1 (left) remains easier to interpret. For example, the ceiling-beams and arched columns generate quite obvious hyperbolic signatures in the primitve radargram at left whereas they have been largely removed in the migrated attribute display at right. For this reason, herein we prefer to make all the interpretations using minimally-processed radargrams. 

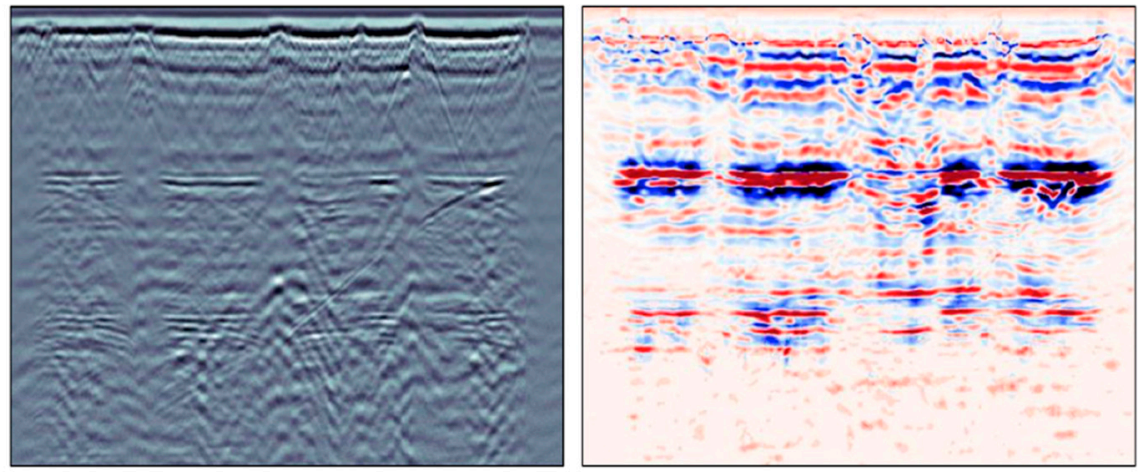

Figure A1. An example of a minimally-processed B-scan (left) that has been subjected to further data processing (right), as described in the text. The dimensions of both radargrams are $13 \mathrm{~m}$ in width and $60 \mathrm{~ns}$ in two-way travel-time. The minimally-processed B-scan at left is the middle portion of the Sunrise Alley B-scan shown in Figure 6a.

\section{References}

1. Moropoulou, A.; Labropoulos, K.C.; Delegou, E.T.; Bakolas, A. Non-destructive techniques as a tool for the protection of built cultural heritage. Construct. Build. Mater. 2013, 48, 1222-1239. [CrossRef]

2. Chastre, C.; Ludovico-Marques, M. Non-destructive testing methodology to assess the conservation of historic stone buildings and monuments. In Handbook of Materials Failure and Analysis; Makhlouf, A.S.H., Aliofkhazraei, M., Eds.; Elsevier: Amsterdam, The Netherlands, 2018; pp. 255-294.

3. Lai, W.W.L.; Xavier, D.; Annan, P. A review of ground-penetrating radar application in civil engineering: A 30-year journey from locating and testing to imaging and diagnosis. NDT E Int. 2018, 96, 58-78.

4. Comina, C.; Sotiropoulos, P.; Maroulakis, S.; Vacha, D.; Mandrone, G.; Masturzo, N.; Matsumoto, N.; Seike, A. Geophysical surveys over and inside the Tobiotsuka kofun-Okayama prefecture. J. Archaeol. Soc. Rep. 2020, 30, 102256. [CrossRef]

5. Warren, C.A.; Giannopoulos, A.; Giannakis, I. gprMax: Open source software to simulate electromagnetic wave propagation for ground penetrating radar. Comput. Phys. Comm. 2016, 209, 163-170. [CrossRef]

6. Davis, J.L.; Annan, A.P. Ground-penetrating radar for high-resolution mapping of soil and stratigraphy. Geophys. Prosp. 1989, 37, 531-551. [CrossRef]

7. Utsi, E.C.; Colls, K.S. The GPR investigation of the Shakespeare family graves. Archaeol. Prosp. 2017, 24, 335-352. [CrossRef]

8. Roberts, R.L.; Daniels, J.J. Analysis of GPR polarization phenomena. J. Eng. Environ. Geophys. 1996, 1, 139-157. [CrossRef]

9. Sassen, D.S.; Everett, M.E. Three-dimensional polarimetric GPR coherency attributes and full-waveform inversion of transmission data for characterizing fractured rock. Geophysics 2009, 74, J23-J34. [CrossRef]

10. Terenzi, G.; Fuso, E.; Spinelli, P.; Costoli, I.; Pieraccini, M.; Miccinesi, L. Ground penetrating radar survey for structural assessment of a heritage sports building. IOP Conf. Ser. Mater. Sci. Eng. 2020, 949, 012031. [CrossRef]

11. Masini, N.; Persico, R.; Rizzo, E. Some examples of GPR prospecting for monitoring of monumental heritage. J. Geophys. Eng. 2010, 7, 190-199. [CrossRef]

12. Johnston, B.; Ruffell, A.; McKinley, J.; Warke, P. Detecting voids within a historical building facade: A comparative study of three high frequency GPR antenna. J. Cult. Herit. 2018, 32, 117-123. [CrossRef]

13. Gil, E.; Mas, A.; Lerma, M.E.; Vercher, J. Non-destructive techniques methodologies for the detection of ancient structures under heritage buildings. Int. J. Architect. Herit. 2019, 1-17. [CrossRef]

14. Udphuay, S.; Paul, V.L.; Everett, M.E.; Warden, R.R. Ground-penetrating radar imaging of 12th century Romanesque foundations beneath the 13th century Gothic abbey church of Valmagne, France. Archaeol. Prosp. 2010, 17, 199-212. [CrossRef]

15. Miccinesi, L.; Beni, A.; Monchetti, S.; Betti, M.; Borri, C.; Pieraccini, M. Ground penetrating radar survey of the floor of the Accademia gallery (Florence, Italy). Remote Sens. 2021, 13, 1273. [CrossRef]

16. Ruiz Guzman, H.; Everett, M.E.; de Smet, T.; Warden, R. The fortress beneath: Ground penetrating radar imaging of the Citadel at Alcatraz: 2. Curvelet analysis. Geophysics. (to appear).

17. Tzanis, A. The curvelet transform in the analysis of 2-D GPR data: Signal enhancement and extraction of orientation-and-scaledependent information. J. Appl. Geophys. 2015, 115, 145-170. [CrossRef]

18. Grassick, M. Historic Furnishings Report, Alcatraz Island: Main Prison Building; National Park Service: Harpers Ferry, WA, USA, $2005 ;$ p. 612.

19. Thompson, E.N. The rock: A history of Alcatraz island, 1847-1972: Historic Resource Study, Golden Gate National Recreation Area; National Park Service, United States Department of the Interior: Denver, CO, USA, 1979; p. 586. 
20. De Smet, T.S.; Everett, M.E.; Warden, R.R.; Komas, T.; Hagin, J.N.; Gavette, P.; Martini, J.A.; Barker, L. The fate of the historic fortifications at Alcatraz island based on terrestrial laser scans and ground-penetrating radar interpretations from the recreation yard. Near Surf. Geophys. 2019, 17, 151-168. [CrossRef]

21. Anderson-Hallas. Alcatraz Island National Historic Landmark Historic Structure Report Update, Main Prison: Citadel Chronology; Anderson-Hallas Architects: Golden, CO, USA, 2017; pp. 2-33.

22. Farneth, S.J.; Sugaya, H.B.; Wessel, D.P.; White, G.O.; Heili, J. Alcatraz Cell House: Historic Structure Report; Architectural Resources Group: San Francisco, CA, USA, 1992; p. $106+$ Appendices.

23. Cassidy, N.J. Ground penetrating radar data processing, modelling and analysis. In Ground Penetrating Radar: Theory and Applications; Jol, H.M., Ed.; Elsevier: Amsterdam, The Netherlands, 2009; pp. 141-176.

24. Conyers, L.B. Discovery, mapping and interpretation of buried cultural resources non-invasively with ground-penetrating radar. J. Geophys. Eng. 2011, 8, S13-S22. [CrossRef]

25. Knott, R. Alcatraz-preserving this national landmark-the secrets revealed. In Proceedings of the Association of Conservation Engineers, Chesterton, IN, USA, 7-11 October 2012.

26. Konigsmark, T. Geological Trips: San Francisco and the Bay Area; Geopress: Gualala, CA, USA, 1998; pp. $46-67$.

27. National Archives and Records Administration. Plad and Sections of Defensive Barracks, Alcatraces Island, Sept. 30 th 1859 [Architectural Drawing]; Fortifications Map File Drawer 95, Sheet 30, Cartographic Records (General) 1820-1848; Records of the Chief of Engineers, Record Group 77; National Archives at College Park: College Park, MD, USA, 1895.

28. Fediuk, A.; Wilken, D.; Wunderlich, T.; Rabbel, W. Physical parameters and contrasts of wooden objects in lacustrine environment: Ground penetrating radar and geoelectrics. Geosciences 2020, 10, 146. [CrossRef]

29. Rodrigues, B.P.; Senalik, C.A.; Wu, X.; Wacker, J. Use of ground penetrating radar in the evaluation of wood structures: A review. Forests 2021, 12, 492. [CrossRef]

30. Alani, A.M.; Lantini, L. Recent advances in tree root mapping and assessment using non-destructive testing methods: A focus on ground penetrating radar. Surv. Geophys. 2020, 41, 605-646. [CrossRef]

31. Flint, R.C.; Jackson, P.D.; McCann, D.M. Geophysical imaging inside masonry structures. NDT E Int. 1999, 32, 469-479. [CrossRef]

32. Angelopoulos, M.; Redman, D.; Pollard, W.H.; Haltigin, T.W.; Dietrich, P. Lunar ground penetrating radar: Minimizing potential data artifacts caused by signal interaction with a rover body. Adv. Space Res. 2014, 54, 2059-2072. [CrossRef]

33. Beres, M.; Haeni, F.P. Application of ground-penetrating-radar methods in hydrogeologic studies. Ground Water 1991, 29 , 375-386. [CrossRef]

34. Van Overmeeren, R.A. Radar facies of unconsolidated sediments in The Netherlands: A radar stratigraphy interpretation method for hydrogeology. J. Appl. Geophys. 1998, 40, 1-18. [CrossRef]

35. Bowling, R.D.; Laya, J.C.; Everett, M.E. Resolving carbonate platform geometries on the island of Bonaire, Caribbean Netherlands through semi-automatic GPR facies classification. Geophys. J. Int. 2018, 214, 687-703. [CrossRef] 